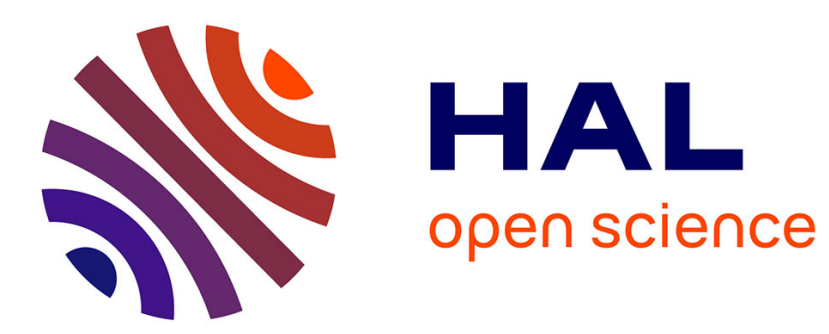

\title{
Homophily, Peer Effects, and Dishonesty
}

Liza Charroin, Bernard Fortin, Marie Claire Villeval

\section{To cite this version:}

Liza Charroin, Bernard Fortin, Marie Claire Villeval. Homophily, Peer Effects, and Dishonesty. 2021. halshs-03187671

\section{HAL Id: halshs-03187671 https://shs.hal.science/halshs-03187671}

Preprint submitted on 1 Apr 2021

HAL is a multi-disciplinary open access archive for the deposit and dissemination of scientific research documents, whether they are published or not. The documents may come from teaching and research institutions in France or abroad, or from public or private research centers.
L'archive ouverte pluridisciplinaire HAL, est destinée au dépôt et à la diffusion de documents scientifiques de niveau recherche, publiés ou non, émanant des établissements d'enseignement et de recherche français ou étrangers, des laboratoires publics ou privés. 
UMR 5824

93. chemin des Mouilles 69130 Ecully - France

Maison de IUniversité, Bâtiment $\mathrm{B}$ 10, rue Trefilerie 42023 Saint-Etienne cedex $02 \cdot$ France http://www.gate.cnrs.fr gate@gate.cnrs.fr

WP 2107 - April 2021

\title{
Homophily, Peer Effects, and Dishonesty
}

\author{
Liza Charroin, Bernard Fortin, Marie Claire Villeval
}

\begin{abstract}
:
If individuals tend to behave like their peers, is it because of conformity, that is, the preference of people to align behavior with the behavior of their peers; homophily, that is, the tendency of people to bond with similar others; or both? We address this question in the context of an ethical dilemma. Using a peer effect model allowing for homophily, we designed a real-effort laboratory experiment in which individuals could misreport their performance to earn more. Our results reveal a preference for conformity and for homophily in the selection of peers, but only among participants who were cheating in isolation. The size of peer effects is similar when identical peers were randomly assigned and when they were selected by individuals. We thus jointly reject the presence of a self-selection bias in the peer effect estimates and of a link strength effect..
\end{abstract}

\section{Keywords:}

Peer Effects, Homophily, Dishonesty, Self-Selection Bias, Experiment

JEL codes:

C92, D83, D85, D91

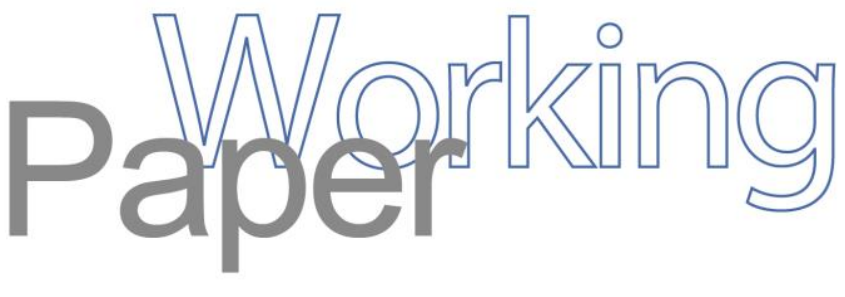




\title{
Homophily, Peer Effects, and Dishonesty*
}

\author{
Liza Charroin ${ }^{\dagger}$ Bernard Fortin ${ }^{\ddagger}$ Marie Claire Villeval ${ }^{\S}$
}

April 2021

\begin{abstract}
If individuals tend to behave like their peers, is it because of conformity, that is, the preference of people to align behavior with the behavior of their peers; homophily, that is, the tendency of people to bond with similar others; or both? We address this question in the context of an ethical dilemma. Using a peer effect model allowing for homophily, we designed a real-effort laboratory experiment in which individuals could misreport their performance to earn more. Our results reveal a preference for conformity and for homophily in the selection of peers, but only among participants who were cheating in isolation. The size of peer effects is similar when identical peers were randomly assigned and when they were selected by individuals. We thus jointly reject the presence of a self-selection bias in the peer effect estimates and of a link strength effect.
\end{abstract}

Keywords: Peer Effects, Homophily, Dishonesty, Self-Selection Bias, Experiment.

JEL-Codes: C92, D83, D85, D91.

${ }^{*}$ We thank Vincent Boucher, Yann Bramoullé, Yan Chen, Alain Cohn, Russell Davidson, Claude Fluet, Steeve Marchand and Bruce Shearer for helpful discussions. We also thank seminar participants at Aix Marseille School of Economics, Beta at Université de Lorraine, CREST in Paris, the Erasmus Institute in Rotterdam, ICES at George Mason University, Laval University, the University of Michigan SBEE seminar, Purdue University, Shandong University, the Universities of Glasgow and Heidelberg, and Virginia Tech University for helpful comments. Aristide Houndetoungan provided exceptional research assistance. We are also grateful to Quentin Thevenet who programmed the experiment. Support for this research was provided by the French National Research Agency (FELIS, ANR-14-CE28-0010-01), the CORTEX Laboratory of Excellence (ANR-11-LABX-0042) of Université de Lyon, within the program Investissements d'Avenir (ANR-11-IDEX-007), and IDEXLYON from Université de Lyon (INDEPTH-IDEX/SBP/2018/03) within the Programme Investissements d'Avenir (ANR-16-IDEX-0005) operated by the French National Research Agency.

${ }^{\dagger}$ Sorbonne Economic Centre, University of Paris 1: liza.charroin@univ - paris1.fr

${ }^{\ddagger}$ Economics Department, Laval University, Québec, CIRPÉE, and CIRANO, Canada. IZA, Bonn, Germany. bernard.fortin@ecn.ulaval.ca, Cell. : 14184738403

$\S$ Univ Lyon, CNRS, GATE UMR 5824, 93 Chemin des Mouilles, F-69130, Ecully, France. IZA, Bonn, Germany. villeval@gate.cnrs.fr 


\section{Introduction}

Most parents care a lot about their children's friendship networks because they fear the negative influence that some peers may exert on their children's behavior. Indeed, there is evidence that unethical behavior disseminates along social networks. For example, some corporate cultures favor weak ethical norms (Egan et al., 2019), certain social interactions encourage criminal acts (Glaeser et al., 1996), and having unethical peers in an academic context increases the individuals' temptation to cheat (Carrell et al., 2008). In the ethical domain, as in other contexts, peer effects may result from a preference for conformity - namely, the tendency of people to align behavior with the behavior of their peers -, because deviating from others' behavior generates a disutility, while conformity brings some advantages (Henrich and Boyd, 1998). ${ }^{1}$ However, similar behavior in a network may also result from people's tendency to gather with others who have similar preferences or characteristics (e.g., age, gender, ethnicity). Homophily may be particularly important in the ethical domain because selecting similar peers might also allow people to choose the social norm that helps them justify their own behavior, independently from any complementarity in the criminal production function. Thus, if some people behave similarly, the cause may be peer effects, homophily, or both.

At the econometric level, the identification of causal peer effects ${ }^{2}$ with observational data is particularly challenging when the formation of networks is endogenous, which usually occurs. Indeed, what one may interpret as peer effects might occur partly because individuals tend to select peers who have characteristics close to theirs; thus, they behave similarly. Homophily may be the source of a self-selection bias that leads to overestimating causal peer effects. The identification of peer effects requires sophisticated econometric techniques that are still being developed (e.g., de Paula, 2017; Graham, 2019). Such a structural approach generally relies on strong identification restrictions that may be difficult to justify. In this paper, we investigate these crucial issues thanks to a lab experiment in which the matching process is perfectly observable and properly manipulated. To test a peer effect model, with and without homophily, and measure the pure impact of conformity on lying behavior, we trade the richness of observational data for a clean manipulation of matching in the lab.

The objectives of our research are threefold. First, we aim to identify pure conformity effects on lying behavior in a setting where various types of peers are exogenously assigned to individuals. We also investigate whether conformity depends on the type of peers, that is, whether there is heterogeneity in peer effects. Notably, individuals may be highly influenced by a given type of peers, but not (or less) by others (e.g., see Xiang et al., 2010; Aral and Walker, 2014; Patacchini et al., 2017). Second, we evaluate the presence of homophily when individuals can select their type of peers. Finally, in the latter case, we test that homophilious preferences affect the estimate of conformity because they are a source of a selection bias or of a link strength effect. This effect

\footnotetext{
${ }^{1}$ Other peer mechanisms may also be at play, such as knowledge spillovers on unethical actions. We ignore them in this study, given the absence of social learning in our experiment. We return to this point in conclusion.

${ }^{2}$ In this paper, we focus on "endogenous" peer effects, that is, the impact of peers' behavior on an individual's behavior, as defined by Manski (1993). For the sake of simplification, we do not study the impact of peers' characteristics ("contextual peer effects").
} 
occurs if people value more the examples of their peers because they have selected them, similar to a control premium.

By attempting to answer these questions, we contribute to the literature on peer effects on unethical behavior, based on observational data (e.g., Ludwig et al., 2001; Patacchini and Zenou, 2009; Damm and Dustmann, 2014), or field and lab experimental data (e.g., Fortin et al., 2007; Keizer et al., 2008; Gino et al., 2009; Rauhut, 2013; Kroher and Wolbring, 2015; Pascual-Ezama et al., 2015; Drago et al., 2020). The extent to which the endogenous network formation affects conformity effects is usually not addressed in these studies (see section 2). In contrast with this literature, the experimental study of Gross et al. (2018) randomly matched individuals with a partner and allowed them to switch partners. Dishonest players switched partners to find a "partner-in-crime", and some honest players took advantage of the situation by retaining a partner who was a liar. By contrast, in our study, there is no complementarity in payoffs; thus, we can study pure conformity effects, and we do so both when the formation of networks is exogenous and when it is endogenous.

We designed an experiment in which participants had to perform a simple task repeatedly for a given piece rate. Before performing this task, they had to choose between two modes of calculation of their earnings performance. ${ }^{3}$ They made this choice only once. Under the Automatic mode, the program directly computed the performance at the end of each period, measuring the actual performance. Under the Manual mode, the participants had to calculate and self-report their performance, providing them some discretion to increase their earnings by cheating. The difference between the reported and the actual performance measured the size of the lies. This opportunity to choose their mode is an important aspect of our design because most previous studies only observed how people succumb to temptation in the presence of cheating opportunities (for an exception, see Konrad et al., 2021).

Our between-subject design implemented three environments: the Baseline treatment (Baseline), the Exogenous treatment (EXO), and the Endogenous treatment (ENDO). Each treatment had two parts. The first and the second parts of the Baseline were identical: individuals performed the task in isolation. This treatment was run first to collect data for the two subsequent treatments. In the first part of EXO and ENDO, individuals also performed in isolation. In the second part of these two treatments, participants were matched with two peers from the Baseline: either peers who both chose the Automatic mode (and thus, could not lie) or peers who both chose the Manual mode (with a cheating opportunity). At the beginning of each period, individuals matched with peers who chose the Automatic mode were informed of these peers' average actual performance in the same period, while individuals matched with peers who chose the Manual mode were informed of these peers' average reported performance. Creating such unidirectional networks with a one-way flow of information from peers to participants removes any simultaneity issue. ${ }^{4}$

\footnotetext{
${ }^{3}$ In real settings people cannot usually choose how their performance is evaluated. But they can selfselect into occupations or sectors that give more or less unethical opportunities of personal enrichment.

${ }^{4}$ This constitutes a major advantage of implementing our study in the lab. Another advantage of this setting is minimizing endogeneity associated with measurement errors (see Angrist, 2014) and partial sampling of the network (see, e.g., de Paula, 2017).
} 
The matching process of individuals with peers was manipulated across treatments. In EXO, each participant was randomly matched with peers, allowing us to estimate a pure conformity effect with no bias, and test whether the effect was heterogeneous depending on the category of peers. In ENDO, the basic difference was that at the beginning of the second part, participants had to choose to be matched for the whole part with two peers who selected either the Automatic mode or the Manual mode. ENDO allowed us to check for the presence of homophily. It also allowed us to compare the conformity effects in EXO and ENDO by means of a joint test to identify the presence of a positive selection bias in the peer effect or of a link strength effect because of the opportunity to select peers.

To estimate conformity effects, we developed a quadratic social interactions model inspired by Ballester et al. (2006) and Calvó-Armengol et al. (2009), where the individual's utility depends on net payoffs, individual characteristics, the moral cost of cheating, and average peers' performance and type (in terms of their chosen mode of evaluation). In this model, the individual's actual performance and size of lies when he chose the Manual mode are both endogenous variables. In ENDO, the model was augmented to account for homophily, which requests introducing a selection equation providing the likelihood of selecting peers who chose the same mode as the individual.

The results of EXO provide evidence of selective peer effects on lying. The size of lies of the individuals who chose the Manual mode increased with the reported performance of their peers. However, this was observed only for individuals with a weak moral type (as revealed by their dishonest behavior when performing the task in isolation in the first part) and only when they were matched with peers who chose the same mode as themselves. This finding may express the loss of utility (or envy) that a liar would suffer if his performance deviated from that of his peers who chose the same mode. By contrast, individuals who chose the Manual mode but did not lie in isolation - individuals who probably have a stronger moral type - did not lie more after observing the reported performance of their peers who potentially lied. They treated this information as irrelevant to their behavior, probably because of stronger ethical values and a higher perceived distance with such peers.

The results of ENDO reveal the presence of homophily but again, only among individuals with a weak moral type. When matching was endogenous, liars were more likely to select peers who also chose the Manual mode than peers who chose the other mode. By contrast, individuals who chose the Automatic mode and individuals who chose the Manual mode and did not lie in the first part did not express any preference for homophilious matching. We interpret this finding as a willingness of liars to form a reference group whose behavior represents a lenient descriptive social norm. ${ }^{5}$ Finally, we found no significant difference in the size of peer effects when the network formation was exogenous and when it was endogenous. This test rejects both the presence

\footnotetext{
${ }^{5}$ Descriptive social norms correspond to the empirical expectations about majority behavior, in contrast to injunctive norms that refer to the perceived approval by the majority of people of a given behavior in given circumstances (see, e.g., Bicchieri, 2012). This revealed preference of liars for peers who also selected the mode that allows cheating is consistent with the fact that when matching was exogenous, conformity was observed only when liars were matched with potential liars.
} 
of a positive self-selection bias because of homophily in the estimation of peer effects on lying, and the existence of a link strength effect motivated by the selection of peers. Overall, our results suggest that endogenous matching does not change the moral type of individuals but may help them choose the social norm they are willing to comply with.

The remainder of this paper is organized as follows. Section 2 briefly reviews the related literature. Section 3 develops in parallel our theoretical model and describes our experimental design. Section 4 presents our experimental results. Finally, section 5 discusses these results and concludes.

\section{Related Literature}

We contribute to at least three strands of the literature: the identification of peer effects when networks are formed endogenously, the identification of homophilious preferences, and the role of peers in the diffusion of unethical behavior.

First, our study complements the literature on peer effects based on observational data. Studies have suggested that if the covariance of crime across regions generally exceeds its variance within regions, this could not only result from economic and social conditions but also from the influence of each agent on his neighbors (Glaeser et al., 1996). Because crime is mutually reinforcing (Schrag and Scotchmer, 1997), criminality may increase exponentially in some neighborhoods but not in others. Patacchini and Zenou (2009) showed strong conformity in juvenile delinquency, using the Add Health database, and Díaz and Patacchini (2020) found that that peer effects on juvenile crime can be lowered by parental engagement (see also Damm and Dustmann, 2014). Haynie (2001) observed the central position in a delinquent network, the density of connections, and popularity influence peer effects. However, these studies do not investigate the issue of the endogeneity of networks, which may bias the identification of peer effects. Various econometric techniques have been recently developed to address this endogeneity issue (see de Paula, 2017, for a recent survey) but they have not been applied to unethical behavior. For example, using a Bayesian method and Markov Chain Monte Carlo simulations, Goldsmith-Pinkham and Imbens (2013) analyzed peers' influence on academic achievement and did not find that unobserved variables are relevant to the outcome. Using, in addition, a Spatial Auto Regression model, Hsieh and Lee (2016) found the opposite: a significant friendship selection bias. Here, the source of endogeneity is the presence of omitted variables that explain network formation and behavior.

That individuals self-select into a network to optimize their utility function has been considered recently. Boucher (2016) proposed a social interaction model with conformity, estimated using an Add Health sample of students who simultaneously chose their participation in extracurricular activities and peers to connect to. He found that network endogeneity has little impact on peer effects. Testing a model in which individuals both choose their peers and the decision to smoke tobacco, Badev (Forthcoming) also found that accounting for the endogeneity of network formation has little impact on the peer effect parameter. Hsieh et al. (Forthcoming) showed that students create more links with good students to increase their chance of academic success. These studies reveal a weak effect of the endogeneity of network formation on behavior, but the results are 
sensitive to the econometric approaches used. Additionally, most econometric methods have limitations. For example, they do not predict well some usual characteristics of social networks, such as the presence of clustering or many sparse networks.

Exploring peer effects on unethical behavior with observational data is particularly challenging when one is willing to account for link formation. At the cost of increased artificiality, using a lab experiment allowed us to design a simple network architecture even when the links that connected individuals were formed endogenously. We were able to test whether the formation of links influences the measure of peer effects with perfect observability of networks and behavior, and with econometric methods that are easier to implement.

Second, our study contributes to the literature on homophily (Currarini et al., 2009; Benhabib et al., 2010; Golub and Jackson, 2012)). Since the study of McPherson et al. (2001) showing that similarity in terms of characteristics, preferences, or beliefs generates connections, most experimental results on homophily are from studies of group identity. Individuals treat in-groups and out-groups differently and favor in-group matching (for a survey, see Li, 2020). For example, in Currarini and Mengel (2016), individuals preferably match with in-groups and homophilious individuals are less reciprocal toward out-groups than in-groups. There is also evidence of assortative matching in the field of criminality (e.g., Haynie, 2001; Knecht et al., 2010; Gavrilova, 2019). For example, Flashman and Gambetta (2014) showed that deviants are more likely to link with other deviants than with non-deviants because it creates mutual obligations in terms of trust. Here, we measure homophily in the context of unethical decision-making without productive complementarity and when matching is based on a signal of past behavior instead of individual attributes. Moreover, our aim is to analyze whether homophily is the source of a self-selection bias in the estimation of causal peer effects and a reinforcer of the strength of the links and, therefore, whether it influences the size of the peer effects.

Finally, our study complements the experimental literature on peer effects on cheating. Keizer et al. (2008) demonstrated that individuals are less likely to comply with a norm when they observe peers violating the norm. In Gino et al. (2009), the presence of a confederate who signals the possibility to cheat increases individuals' dishonesty (see also Fosgaard et al., 2013). Information on the dishonesty of others increases lying (see Robert and Arnab (2013) in a sender-receiver game, Rauhut (2013) and Kroher and Wolbring (2015) in die games, Bäker and Mechtel (2019) and Lauer and Untertrifaller (2019) in real-effort tasks). In a field experiment on information transmission in networks, Drago et al. (2020) showed that, on the other hand, informing targeted individuals on the risk of sanctions in case of detected fraud can generate large spillover effects on untreated neighbors. However, peer effects are not always observed (Fortin et al., 2007; Diekmann et al., 2015; Abeler et al., 2019); they are asymmetric because bad examples are more contagious than good examples (Lefebvre et al., 2015); and norm compliance may depend on the proximity with peers (Bicchieri et al., 2019). In these studies, peers are exogenously assigned, whereas in real settings individuals can choose their peers. By contrast, Gross et al. (2018) allowed individuals to change partners in a repeated dyadic die-rolling task. Pascual-Ezama et al. (2015) invited real friends and demonstrated that peer effects depend on the number of peers cheating. Our study differs from those in several respects: we exclude payoff complementary between co-players 
and compare lying in isolation and in the presence of endogenous and exogenous social interactions.

\section{Theoretical Model and Experimental Design}

We present our experimental design and the model in the same section because they are tightly connected. We start by describing the task performed by the participants in each of the two parts of the experiment. Next, we introduce the three different treatments that allowed us to measure peer effects, homophily, and the existence of a self-selection bias or a link strength effect in the estimation of causal peer effects. Figure 1 displays the timeline of the experiment.

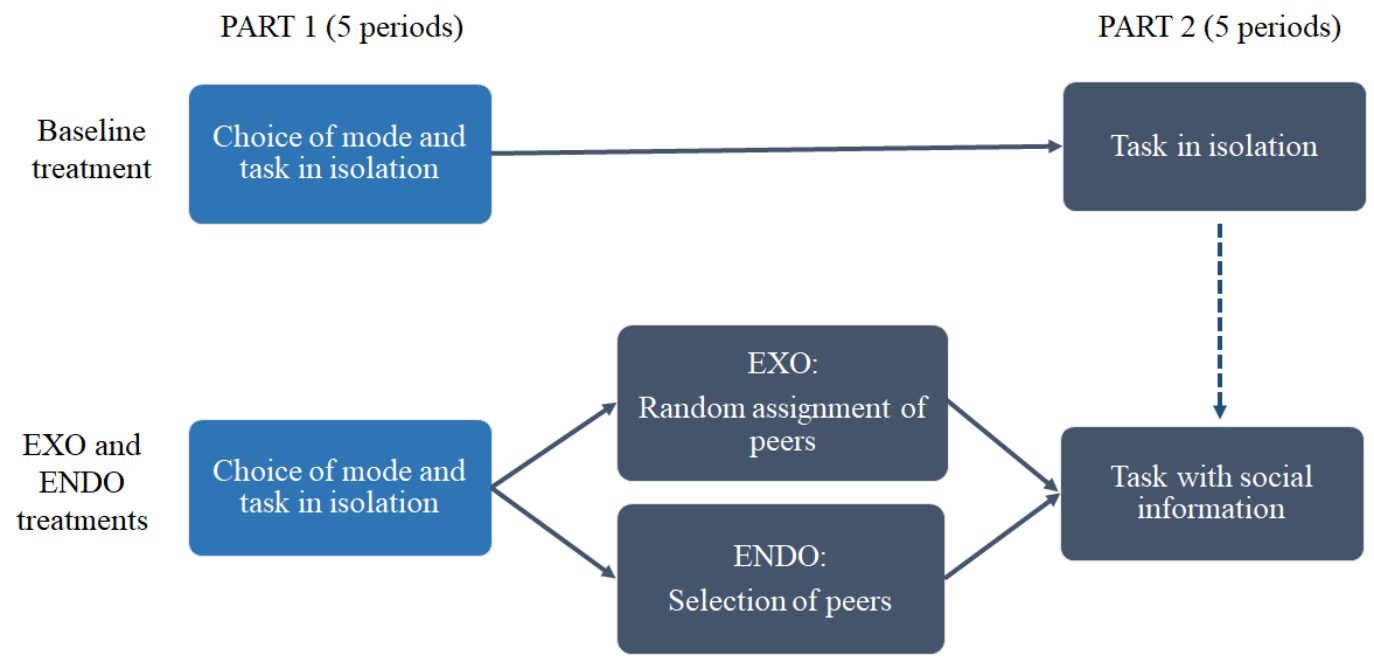

Figure 1: Timeline of the Experiment

\subsection{The Task}

In all treatments, participants had to perform the Grid task introduced by Falk et al. (2006). In each period, they had two minutes to count the number of 0 s in grids that only contain $0 \mathrm{~s}$ and $1 \mathrm{~s}$. This task did not require any prior knowledge, and its purpose was capturing differences in effort, not ability. Grids appeared one by one on the screens. After the participant validated an answer, correct or not, a new grid was displayed. Individuals could see a maximum of 20 grids in each period. ${ }^{6}$ For a reason explained later, the grids had two sizes, each associated with a different piece rate: $5 \times 5$ grids paid 1 point, and $5 \times 10$ grids paid 2 points if solved correctly (see illustrations in Figure A.1 and Figure A.2). The sequence of grids was randomly generated before the experiment, and every participant received the same grids in the same order, such that actual performances are perfectly comparable across individuals.

\footnotetext{
${ }^{6}$ This limit was not constraining since only two participants over 369 managed to solve 20 grids in two minutes, and they did so only once.
} 
At the end of each period, a feedback table was displayed on the participant's screen (see Figure A.3 and Figure A.4). Each line corresponded to a grid with, in columns, its piece rate, the answer provided by the participant and the correct answer. We defined performance in a period as the sum of points earned in this period. Thus, the actual performance is obtained by summing the number of grids solved, multiplied by their corresponding piece rate. This task was repeated (with different grids) in each period of the two parts that we now describe successively.

\subsection{Part 1: Mode Choice and Task Performance in Isolation}

Part 1 was similar across treatments. At the beginning of part 1, participants had to practice the task we have just described for two minutes, and they were able to observe an example of the feedback table. Next, they had to choose between two modes of performance evaluation: the Automatic and the Manual modes. ${ }^{7}$ Choosing the Automatic mode meant that their performance was automatically computed and recorded by the program. Choosing the Manual mode meant that they had to calculate and report themselves their performance in the computer. Based on the feedback table (see Figure A.4 in Appendix), they had to check whether they solved each grid and sum the number of points earned depending on the corresponding piece rates. This action required additional effort but this mode also created a cheating opportunity because participants could then misreport their performance. If this mode was selected, we measured the actual performance and the size of lies, provided by the difference between the actual and the reported performances. ${ }^{8}$ We used two grid sizes to increase the opportunity (cognitive) cost of choosing the Manual mode if an individual does not intend to cheat. Thus, participants had to not only check whether each answer was correct but also apply the piece rate corresponding to the grid size.

After choosing the mode that would apply throughout the part, participants, who we assume for simplicity to be myopic, had to perform the task in isolation during five periods of two minutes each. At the end of each period, depending on the mode chosen, they had or not to report their number of points earned.

This design can be formally represented as follows. In part 1, we assume that the utility function of an individual choosing the Automatic mode is quadratic (see Ballester et al., 2006; Calvó-Armengol et al., 2009; Boucher and Fortin, 2016) and given by

$$
U_{i t}=\left(\mathbf{x}_{i}^{\prime} \boldsymbol{\beta}+\epsilon_{i t}\right) p_{i t}-\frac{p_{i t}^{2}}{2},
$$

where $p_{i t}$ denotes the actual performance of individual $i$ in period $t, \mathbf{x}_{i}^{\prime}$ is a vector of individual exogenous characteristics ${ }^{9}$ that are constant over time, $\boldsymbol{\beta}$ are the associated

\footnotetext{
${ }^{7}$ In the instructions (see Appendix A1), the Automatic mode was called the Direct mode and the Manual mode was called the Indirect mode.

${ }^{8}$ To avoid a demand effect, the instructions used neutral wording (see Appendix A1). Participants had to figure out by themselves that over-reporting was feasible. We checked the understanding of the rules by means of questionnaires but without refereeing to the possibility of cheating (see Appendix A2). Moreover, we did not explicitly informed the participants that we were able to measure the size of their lies but they could figure this out since we provided them with the actual performance feedback for each grid and they reported their performance in the computer.

${ }^{9}$ In the experiment, these characteristics include age, gender, degree, school, monthly expenses and whether the participant participates in a lab experiment for the first time.
} 
parameters, and $\epsilon_{i t}$ is the disturbance term reflecting unobserved heterogeneity. The expression $p_{i t}^{2} / 2$ represents the convex cost of effort. Assuming an interior solution, the first-order condition is linear and given by

$$
p_{i t}=\mathbf{x}_{i}^{\prime} \boldsymbol{\beta}+\epsilon_{i t} .
$$

We assume that the utility function of an individual choosing the Manual mode is also quadratic and given by

$$
V_{i t}=\left(\mathbf{x}_{i}^{\prime} \tilde{\boldsymbol{\beta}}+\tilde{\epsilon}_{i t}\right) p_{i t}-\frac{p_{i t}^{2}}{2}+\left(\mathbf{x}_{i}^{\prime} \boldsymbol{\alpha}+\mu_{i t}\right) l_{i t}-\frac{l_{i t}^{2}}{2}+\left(\mathbf{x}_{i}^{\prime} \boldsymbol{\kappa}+\psi_{i}\right)
$$

The first two terms of the right-hand side of (3) reflect the sub-utility associated with the actual performance and its effort cost. The impact of an increase in performance might differ according to the chosen mode, because of the cost of the cognitive effort requested to compute payoffs manually in the Manual mode. This impact may also vary by individuals' characteristics $\left(\tilde{\boldsymbol{\beta}} \neq \boldsymbol{\beta}\right.$ and $\left.\tilde{\epsilon}_{i t} \neq \epsilon_{i t}\right)$. The last three terms characterize the sub-utility of choosing the Manual mode and of lying. The variable $l_{i t}$ denotes the size of a lie for individual $i$ in period $t$, defined as the difference between $r_{i t}$, the reported performance, and $p_{i t}$, the actual performance. $\boldsymbol{\alpha}$ is a vector of parameters associated with $\mathbf{x}_{i}$, and $\mu_{i t}$ reflects unobservable heterogeneity. Over-reporting performance is the source of additional payoffs but may be morally costly because it violates a moral norm. We assume a convex cost of cheating $\left(=l_{i t}^{2} / 2\right)$. The last term reflects the net fixed benefits (or costs) of choosing the Manual mode. The benefits might be from the value of controlling the computation of payoffs, from retaining the option of lying or not, or from signaling to the experimenter that an individual's type is moral if he chooses the Manual mode but does not lie. The costs might be from having to compute one's performance or resisting the temptation to lie if one's type is moral, or it might represent the reputational cost of choosing a mode that allows lying. The net benefits depend on the individual's observable and unobservable characteristics $\left(=\mathbf{x}_{i}^{\prime} \boldsymbol{\kappa}+\psi_{i}\right)$.

Consistent with the literature on lying, we assume that the individuals who choose the Manual mode never under-report their performance. ${ }^{10}$ Therefore, the inequality constraint, $l_{i t} \geq 0$, is assumed to hold. We suppose that $p_{i t}>0$, that is, even under the Manual mode, individuals are willing to put effort into performing the task. The literature has shown that full lying is rare because of self-concept maintenance or perceived cheating aversion (e.g., Fischbacher and Föllmi-Heusi, 2013; Dufwenberg and Dufwenberg, 2018; Gneezy et al., 2018; Abeler et al., 2019). ${ }^{11}$

The first-order Kuhn-Tucker conditions associated with maximizing (3) with respect to $p_{i t}$ and $l_{i t}$ can be written as

\footnotetext{
${ }^{10}$ Therefore, we consider under-reports occurring in the experiment as mistakes. Indeed, we acknowledge that in the experiment people could make honest mistakes in reporting their performance. While we cannot distinguish whether an over-report is a lie or a mistake, the frequency of under-reports allows us to estimate the frequency of mistaken over-reports, as mistakes should be symmetric. Footnote 23 in the results section shows that their occurrence is relatively rare.

${ }^{11}$ Our empirical results are consistent with this assumption: full lying (i.e, exerting no effort at all but reporting 20 grids solved) only occurred 5 times in part 1.
} 


$$
\begin{aligned}
p_{i t} & =\mathbf{x}_{i}^{\prime} \tilde{\boldsymbol{\beta}}+\tilde{\epsilon}_{i t}, \\
l_{i t}^{*} & =\mathbf{x}_{i}^{\prime} \boldsymbol{\alpha}+\mu_{i t}, \\
\text { with } l_{i t} & =\mathbf{I}\left(l_{i t}^{*}>0\right) l_{i t}^{*},
\end{aligned}
$$

where $l_{i t}^{*}$ is the latent variable associated with the size of lies, and the indicator function $\mathbf{I}(\cdot)$ takes value 1 when $l_{i t}^{*}>0$ and 0 otherwise. Due to the assumption that $p_{i t}>0$, one has $0 \leq l_{i t}<r_{i t}$.

Finally, we use eq. (3) with $p_{i t}=l_{i t}=0$, and obtain the optimal mode choice from the following equations:

$$
\begin{aligned}
V_{i 0} & =\mathbf{x}_{i}^{\prime} \boldsymbol{\kappa}+\psi_{i}, \\
\text { with } M_{i} & =\mathbf{I}\left(V_{i 0}>0\right),
\end{aligned}
$$

where $V_{i 0}$ can be interpreted as the (latent) utility of choosing the Manual mode net of the reserve utility of choosing the Automatic mode (normalized to 0). In eq. (8), $M_{i}$ is a dummy variable equal to 1 if $V_{i 0}>0$, in which case the individual chooses the Manual mode, and equal to 0 otherwise, in which case he chooses the Automatic mode.

\subsection{Part 2: Introduction of Social Interactions}

In part 2, participants had to perform the same task during five periods of two minutes each, under the same mode as in part 1. Part 2 differed from part 1 across three between-subjects treatments. In the Baseline, individuals performed again the task in isolation. In the EXO treatment, they were exogenously matched with two peers from the Baseline who selected either the Automatic or the Manual mode, and they were informed of the mode and the average performance of these peers at the beginning of each period. ENDO was similar to EXO, except that participants had to choose their two peers. We now describe each treatment in detail.

\subsubsection{Baseline}

In the Baseline, after a five-minute break after part 1 (to mimic the timeline of the other treatments), participants performed again the task in isolation. Formally, utility in this treatment is defined in part 2 exactly as it is in part 1 (see eq.(1)). These participants represent the pool of peers that were matched with participants in the other treatments. For that reason, the data of the Baseline were collected first. By matching participants in the Baseline with participants in the other treatments, we formed unidirectional networks where information on average actual or reported performance flowed one-way from peers in the Baseline to individuals in the treatments with social information, which avoided any simultaneity issues in the estimation of peer effects.

\subsubsection{Exogenous Treatment}

In EXO, at the beginning of part 2, participants were exogenously matched with peers from the Baseline according to the following procedure. Each participant first received 
information on the average earnings in part 1 of two pairs of peers from the Baseline. One pair comprised peers who chose the Automatic mode (thus, their earnings indicated their average actual performance), and the other pair comprised peers who chose the Manual mode (thus, their earnings indicated their average reported performance). We provided these two averages to make it clearer to the participants that the Manual mode led to a reported performance probably inflated by cheating. ${ }^{12}$ Next, each participant was randomly and equiprobably matched with one of these two pairs. These directed networks remained fixed throughout part 2. Thus, there were four categories of individuals defined by the mode(s) chosen by the participants and by their peers.

At the beginning of each period in part 2, the participants were informed of the average performance of their two peers in the same period of part 2 (when seeing the same grids). To be consistent with the properties of a linear-in-means model of peer effects, we provided them the average performance instead of the performance of each peer separately. If the participants were matched with peers who selected the Automatic mode (respectively, the Manual mode), it was common knowledge that they observed the average actual (respectively, reported) performance of the peers. If peers selected the Manual mode, participants were not informed of the existence and size of lies (formally, they knew the value of $r_{-i t}$ but not that of $p_{-i t}$ and $\left.l_{-i t}\right) .{ }^{13}$ After observing the average performance of their peers, participants had to perform the task. They were paid based on their individual performance, as they were in part 1.

Formally, the individuals' utility in this treatment depends on their actual performance, their lies (if any), and the actual or reported performance of their peers. Specifically, we use a model of conformity where the individuals' social sub-utility depends on the gap between their behavior and the behavior of their peers (e.g., Boucher and Fortin, 2016; Ushchev and Zenou, 2020). ${ }^{14}$ Observing peers' performance under a given evaluation mode generates a reference point: to increase their utility, individuals may conform to their peers to reduce the distance with them. Next, we consider each utility function successively, depending on the chosen mode.

\section{The individual chooses the Automatic mode}

In this case, the individual's utility function is given by

$$
U_{i t}^{E X O}=U_{i t}-\left(1-m_{-i}\right) \frac{\lambda_{1}}{2}\left(p_{i t}-\bar{p}_{-i t}\right)^{2}-m_{-i} \frac{\lambda_{2}}{2}\left(p_{i t}-\bar{p}_{-i t}^{e}\right)^{2},
$$

\footnotetext{
${ }^{12}$ Pairs could not be of mixed type because the information about average performance would be harder to interpret. In EXO, the observed average actual performance of pairs that selected the Automatic mode in part 1 was 12.84 points $(\min =6.2, \max =18.8)$ and the average reported performance of pairs that selected the Manual mode was 21.26 points $(\min =11.3$, $\max =38.9)$. In $90 \%$ of the cases, individuals observed an average reported performance of the pair that selected the Manual mode greater than the average actual performance of the pair that selected the Automatic mode. The mean difference between the two averages was 8.42 points.

${ }^{13}$ We chose not to inform players directly about the average size of lies for two reasons. First, it could have created an experimenter demand effect. Second, in real settings most of the time one can only suspect the existence of cheating and the size of lies is not directly visible. This is notably the case with credence goods where the quality of a service is usually not verifiable.

${ }^{14}$ This results in a linear-in-means model. Note that a linear-in-sums model may be more appropriate to take into account the synergy effects of peers on aggregate outcomes (e.g., Bramoullé et al., 2014). But this does not apply to our settings.
} 
where the first expression on the right-hand side is the individual's private sub-utility function, the sum of the two other expressions represents his social sub-utility function, and $m_{-i}$ is an exogenous binary variable that is equal to 0 if peers chose the Automatic mode and 1 if they chose the Manual mode.

In the presence of (weak) conformity, $\lambda_{1} \geq 0$ : the individual's social sub-utility decreases when peers chose the Automatic mode, and the (Euclidian) distance between the individual's actual performance and the average actual performance of his peers becomes larger. Moreover, $\lambda_{2} \geq 0$ : the individual's social sub-utility decreases when peers chose the Manual mode, and the distance between his actual performance and the average expected performance of his peers, $\bar{p}_{-i t}^{e}$, increases. The latter variable is not perfectly known by the individual who only receives an imprecise signal of the average actual performance when peers select the Manual mode, that is, their average reported performance. We assume that an individual forms his expectation of $\bar{p}_{-i t}$ as an increasing function of the average performance reported by his peers: $\bar{p}_{-i t}^{e}=\phi\left(\bar{r}_{-i t}\right)$, with $\phi(0)=0, \phi^{\prime}\left(\bar{r}_{-i t}\right) \geq 0$, and $0 \leq \bar{p}_{-i t}^{e} \leq \bar{r}_{-i t}$. As a first-order approximation, we assume that $\bar{p}_{-i t}^{e}=\delta \bar{r}_{-i t}$, where $\delta$ is the expectation coefficient, with $0 \leq \delta \leq 1$. Assuming that individuals form accurate beliefs on the actual performance of their peers, the difference between $\lambda_{1}$ and $\lambda_{2}$ indicates whether individuals put a different weight on their peers depending on the origin of their performance when they choose their level of effort.

The first-order condition yields the following best response function:

$$
p_{i t}=\frac{\mathbf{x}_{i}^{\prime} \boldsymbol{\beta}+\left(1-m_{-i}\right) \lambda_{1} \bar{p}_{-i t}+m_{-i} \lambda_{2} \delta \bar{r}_{-i t}+\epsilon_{i t}}{\Delta_{1}},
$$

where $\Delta_{1}=1+\left(1-m_{-i}\right) \lambda_{1}+m_{-i} \lambda_{2} \geq 1$. Eq.(10) indicates that in the presence of conformity, the average peers' (actual or reported) performance has a positive impact on the individual's actual performance. The expression $\lambda_{1} /\left(1+\lambda_{1}\right)$ represents the effect of the average actual performance from peers who chose the Automatic mode $\left(m_{-i}=0\right)$; $\lambda_{2} \delta /\left(1+\lambda_{2}\right)$ represents the effect of the reported performance from peers who chose the Manual mode $\left(m_{-i}=1\right)$.

\section{The individual chooses the Manual mode}

In this case, the individual's payoff depends on his reported performance, $r_{i t}$, composed of his actual performance, $p_{i t}$, and his lies of size $l_{i t}$. We assume that both components can be influenced by peers. The individual's utility function is given by

$$
\begin{aligned}
V_{i t}^{E X O}=V_{i t}-\left(1-m_{-i}\right) \frac{\lambda_{3}}{2}\left(p_{i t}-\bar{p}_{-i t}\right)^{2}- & \left(1-m_{-i}\right) \frac{\lambda_{4}}{2} l_{i t}^{2} \\
& -m_{-i} \frac{\lambda_{5}}{2}\left(p_{i t}-\bar{p}_{-i t}^{e}\right)^{2}-m_{-i} \frac{\lambda_{6}}{2}\left(l_{i t}-\bar{l}_{-i t}^{e}\right)^{2},
\end{aligned}
$$

where the first expression on the right-hand side is the individual's private sub-utility function, and the sum of the four other expressions denotes his social sub-utility function.

If the individual is matched with peers who chose the Automatic mode, he observes their average actual performance, $\bar{p}_{-i t}$. In the presence of conformity, he can increase 
his social sub-utility by reducing the gap between his actual performance and the average actual performance of his peers by adjusting his effort level (an effect denoted $\lambda_{3} \geq 0$ ) or by reducing the size of his lies (an effect denoted $\lambda_{4} \geq 0$ ). On the opposite, a willingness to mark a difference with peers who chose the opposite mode might lead an individual to reduce his effort and increase his lies $\left(\lambda_{3}<0\right.$ and $\left.\lambda_{4}<0\right)$. If the individual is matched with peers who chose the Manual mode, he can increase his social sub-utility by reducing the gap between his actual performance and the mean expected actual performance of his peers. This effect is denoted $\lambda_{5} \geq 0$. He can also increase his social sub-utility by reducing the gap between his lies and the average expected lies of his peers. This effect is denoted $\lambda_{6} \geq 0$. In other words, in the presence of conformity, the individual's lying behavior is not influenced by the expected actual performance of peers but by their expected misreporting behavior.

The first-order Kuhn-Tucker conditions of (11) yield the following best response functions:

$$
\begin{aligned}
p_{i t} & =\frac{\mathbf{x}_{i}^{\prime} \tilde{\boldsymbol{\beta}}+\left(1-m_{-i}\right) \lambda_{3} \bar{p}_{-i t}+m_{-i} \lambda_{5} \delta \bar{r}_{-i t}+\tilde{\epsilon}_{i t}}{\Delta_{2}}, \\
l_{i t}^{*} & =\frac{\mathbf{x}_{i}^{\prime} \boldsymbol{\alpha}+m_{-i} \lambda_{6}(1-\delta) \bar{r}_{-i t}+\mu_{i t}}{\Delta_{3}}, \quad \text { when } m_{-i}=0 \\
& =\frac{\mathbf{x}_{i}^{\prime} \boldsymbol{\alpha}+\mu_{i t}}{1+\lambda_{4}}, \quad \text { when } m_{-i}=1 \\
& =\frac{\mathbf{x}_{i}^{\prime} \boldsymbol{\alpha}+\lambda_{6}(1-\delta) \bar{r}_{-i t}+\mu_{i t}}{1+\lambda_{6}}, \text { w }
\end{aligned}
$$

with $l_{i t}=\mathbf{I}\left(l_{i t}^{*}>0\right) l_{i t}^{*}$,

where $\Delta_{2}=1+\left(1-m_{-i}\right) \lambda_{3}+m_{-i} \lambda_{5} \geq 1$ and $\Delta_{3}=1+\left(1-m_{-i}\right) \lambda_{4}+m_{-i} \lambda_{6} \geq 1$. Eq. (12) indicates that an increase in the average peers' performance (actual or reported) observed by individual $i$ will increase his actual performance. The expressions $\lambda_{3} /\left(1+\lambda_{3}\right)$ and $\lambda_{5} \delta /\left(1+\lambda_{5}\right)$ represent the effects of the average actual and reported performance of peers on the individual's actual performance, in the case of peers choosing the Automatic or the Manual mode, respectively.

Our model suggests that the size of lies, our primary focus, depends on the individual's characteristics and on his peers' expected behavior. When the individual is matched with peers who chose the Automatic mode $\left(m_{-i}=0\right)$, he knows that they did not lie. In such a case, our conformity model predicts that the size of lies does not depend on peers' performance, but only on being matched with peers who behaved honestly (due to the impact of $1+\lambda_{4}$ on $l_{i t}^{*}$ in eq. $\left(13^{\prime}\right)$ ). ${ }^{15}$

When the individual is matched with peers who chose the Manual mode $\left(m_{-i}=\right.$ 1), conformity implies that he will increase the size of his lies when their reported performance becomes higher. We assume that reason for this is that the individual

\footnotetext{
${ }^{15}$ Note that if peer effects were driven by inequality aversion, individuals should adjust their lying behavior to the actual performance of their peers who chose the Auto mode. This is different from the model of conformity we develop here.
} 
forms an expectation of his peers' lying behavior as a proportion of their average reported performance. In eq. $\left(13^{\prime \prime}\right)$, the expression $\lambda_{6}(1-\delta) /\left(1+\lambda_{6}\right) \geq 0$ represents the effect of peers' average reported performance under the Manual mode on the individual's lying behavior. ${ }^{16}$ This can be understood intuitively: if someone observes that other people who selected an environment that allows them to lie report a higher performance, he can infer that these people probably have lied. This may change the perception of the norm and work as a self-excusing justification for individuals over-reporting their performance.

Proposition 1 (Peer Effects on Lying) (a) The lying behavior of an individual who chose the Manual mode is not influenced by his peers' performance when they have chosen the Automatic mode $\left(m_{-i}=0\right)$. (b) By contrast, when peers have chosen the Manual mode $\left(m_{-i}=1\right)$, in the presence of preferences for conformity, lies increase with peers' reported performance.

- Proof: (a) When $m_{-i}=0, \bar{p}_{-i t}$ does not appear in eq. $\left(13^{\prime}\right)$. This implies that the average performance of peers who selected the Automatic mode does not influence the individual's size of lies. (b) Since $\lambda_{6}(1-\delta) /\left(1+\lambda_{6}\right) \geq 0$ in eq. (13"), the effect of the mean performance reported by peers who selected the Manual mode $\left(m_{-i}=1\right)$ is positive on the individual's size of lies.

\subsubsection{Endogenous Treatment and Homophily}

Similar to EXO, participants in ENDO performed the task in isolation in part 1, they were matched with two peers in part 2 , and they received information on the average peers' performance in the same period at the beginning of each of the five periods of this part. In contrast with EXO, they had to choose between two pairs of peers at the beginning of part 2. They were presented with the average actual performance in part 1 of a pair of peers who selected the Automatic mode and the average reported performance of a pair of peers who chose the Manual mode. By selecting one pair, they either chose to observe the average actual performance in each new period of the peers that selected the Automatic mode or the average reported performance of the peers that selected the Manual mode. ${ }^{17,18}$

At the individual level, homophily is assumed to be present when an individual selects peers who chose the same mode as him, to maximize his utility. However, at the researcher level, a component of the individual's preferences is random because of unobservable heterogeneity. Therefore, we assume that homophily is present when the

\footnotetext{
${ }^{16} \lambda_{6}(1-\delta) /\left(1+\lambda_{6}\right)$ is identifiable in equation $\left(13^{\prime \prime}\right)$ but not $\lambda_{6} /\left(1+\lambda_{6}\right)$ (or $\left.\lambda_{6}\right)$ since the expectation coefficient, $\delta$, is not identifiable.

${ }^{17}$ In ENDO, the observed average actual performance in part 1 of pairs that selected the Automatic mode was 12.91 points $(\min =6.1, \max =18.5)$, and the average reported performance of pairs that selected the Manual mode was 20.55 points $(\min =12$, $\max =38.9)$. In $91 \%$ of the cases, individuals in ENDO observed an average reported performance of the pair that selected the Manual mode greater than the average actual performance of the pair that selected the Automatic mode. The mean difference between the two averages was 7.64 points.

${ }^{18}$ To avoid that the choice of a given pair was driven purely by curiosity about the reported performance of potential cheaters, participants were informed upfront that they would receive at the end of the session information about the mean performance in each period of the pair of peers that they did not select. In such a way, the quantity of information about the selected peers and the non-selected peers was the same, regardless of the choice of the participants; this information was simply displayed at different points in time. For symmetry reasons, we also provided this information in EXO.
} 
individual's likelihood of choosing peers who selected the same mode is higher than chance. Two main reasons can influence such a homophilious choice.

The first reason that individuals might be willing to be matched with peers who chose the same mode as they did is the activation of a feeling of similarity and group identity (for preference-based models of group identity, see Akerlof and Kranton (2000); for selection based on weak signals, see Efferson et al. (2008)). Formally, suppose an individual $i$ does not like to compute his payoffs manually and values honesty. Therefore, he chooses the Automatic mode. This variable is a predetermined variable in the model. Now, he must select a pair of peers on the basis of the information on their chosen mode and their average performance in part 1. Conditional on his choice of the Automatic mode, his (latent) utility of selecting peers who also chose the Automatic mode ("AA" matching) is assumed to be given by

$$
a_{i}^{*}=\mathbf{a}_{1} \mathbf{x}_{i}^{\prime}+a_{2} P_{i}^{A}+a_{3} P_{i}^{M}+a_{4}\left|P_{i}^{A}-P_{i}^{M}\right|+\xi_{i},
$$

where $P_{i}^{A}$ and $P_{i}^{M}$ are the average actual performance in part 1 of the peers who chose the Automatic mode and the average reported performance of the peers who chose the Manual mode, respectively. $\xi_{i}$ is the random term. The expression in absolute value introduces a potential nonlinearity in the effects of the peers' actual and reported performance. All the right-hand side variables are exogenous. Assuming that his reserve utility of selecting the peers who chose the Manual mode is 0 , the decision to select the peers who chose Automatic is given by

$$
a_{i}=\mathbf{I}\left(a_{i}^{*}>0\right),
$$

where $a_{i}$ is a dummy variable equal to 1 if the individual who chose the Automatic mode selects the peers who made the same choice and equal to 0 otherwise. Next, we suppose that eq. (15) and eq. (16) are estimated by using a linear probability model. We also assume, for notational simplicity, that the mean of all the right-hand side variables is normalized to 0 over the relevant population. Then, a majority of the population who chose the Automatic mode in ENDO will be homophilious if, at the average of the explanatory variables (normalized to 0 ), the constant of the regression is larger than 0.5: $E\left[E\left(a_{i}\right) \mid \mathbf{x}_{i}, P_{i}^{A}, P_{i}^{M}\right]>0.5$. Not rejecting this hypothesis indicates that a majority of participants who chose the Automatic mode prefer to select peers with the same mode choice and, therefore, are homophilious.

Although the first motivation for homophily (similarity) also applies to individuals who chose the Manual mode, a second reason for homophily concerns the individuals who selected the Manual mode and lied in part 1 . These people may be less attracted by peers who selected a different mode because being exposed to people who committed not to lie recalls the injunctive moral norm of honesty and makes one's misconduct more salient. This captures the idea of willful ignorance of inconvenient information. By contrast, if peers' behavior is perceived as a signal of an empirical norm, observing others reporting a higher performance may help liars convince themselves that over-reporting their performance is merely what the majority of others probably do, generating additional utility. Individuals who chose the Manual mode and did no lie do not need such arguments. We thus expect some homophily in ENDO, namely, even more among liars 
whose homophilious choice may serve to self-excuse their past and future misconduct.

Conditional on choosing the Manual mode and given the information on the mode and performance of peers in part 1, the (sub-)utility of player $i$ who selects peers who chose the Manual mode is

$$
m_{i}^{*}=\mathbf{x}_{i}^{\prime} \mathbf{b}_{1}+b_{2} P_{i}^{A}+b_{3} P_{i}^{M}+b_{4}\left|P_{i}^{A}-P_{i}^{M}\right|+b_{5} D_{i}^{D}+\eta_{i},
$$

where $D_{i}^{D}$ is a predetermined dummy variable equal to one if the individual lied in part 1 and zero otherwise. Consistent with our aforementioned argument, we assume that $b_{5} \geq 0$, that is, if the individual chose the Manual mode and lied, his utility increases when he selects peers who also chose the Manual mode.

Assuming that his reserve utility when selecting peers who chose the Automatic mode is zero, the decision to select the peers who chose the Manual mode is given by

$$
m_{i}=\mathbf{I}\left(m_{i}^{*}>0\right) .
$$

Again, we assume that eqs. (17) and (18) are estimated by using a linear probability model and that the regressors are normalized so that their average over the relevant population is 0. Then, a majority of the Manual population in ENDO will be homophilious if, at the average of the explanatory variables $(=\mathbf{0})$, the constant of the regression is larger than 0.5: $E\left[E\left(m_{i}\right) \mid \mathbf{x}_{i}, P_{i}^{A}, P_{i}^{M}, D_{i}^{D}\right]>0.5$. This analysis leads to proposition 2 .

Proposition 2 (Preference for Homophily) (a) In ENDO, individuals prefer to be matched with participants that selected the same mode as the individuals selected. (b) The preference for homophily is stronger among individuals who chose the Manual mode and lied than among the other individuals who chose the Manual mode.

- Proof: (a) This is a simple consequence of the hypothesis that $E\left[E\left(a_{i}\right) \mid \mathbf{x}_{i}, P_{i}^{A}, P_{i}^{M}\right]>$ 0.5 for the participants who chose the Automatic mode and $E\left[E\left(m_{i}\right) \mid \mathbf{x}_{i}, P_{i}^{A}, P_{i}^{M}, D_{i}^{D}\right]>$ 0.5 for those who chose the Manual mode. (b) This is a hypothesis that we test by comparing the preference for homophily between individuals who lied and other individuals who chose the Manual mode, that is, by testing that $b_{5} \geq 0$ in eq. (17).

\subsubsection{Endogenous Treatment, Self-Selection Bias, and Link Strength Effect}

Endogenous matching and homophily may influence the measure of the conformity effect on lying through two possible effects: self-selection bias in the peer effect and a link strength effect. First, a self-selection bias in the conformity effect may occur in ENDO if people report a similar performance as their peers not because of causal peer effects on behavior, but because they have selected peers with similar characteristics or preferences. In EXO, by contrast, by design, there is no self-selection bias in peer effects, because peers were exogenously assigned. The second effect of endogenous matching on the size of peer effects on lying may occur if people value the examples of their peers more when they have actively selected them: for psychological reasons such as a control premium, the choice of peers would give these peers a higher weight in the decision process. This effect is not the source of a bias, but its presence indicates that the causal 
peer effects might depend on the strength of the links.

If present, these two effects would move the estimation of peer effects in the same direction. Thus, a simple strategy is pooling the data of individuals who observed the performance of peers who chose the Manual mode and testing whether the significance and magnitude of the peers' reported performance on the size of lies differ in EXO and ENDO. This offers a joint test of the two effects. If the influence of peers' reported performance on the individual's size of lies is statistically indistinguishable in the two treatments, we can reject both the self-selection bias in the peer effects and the link strength effect.

In our experimental study, including endogenous link formation (see, e.g., Bramoullé et al., 2020) in the model is not necessary, because a simple econometric strategy is available to provide a joint test of the absence of homophily bias on peer effect and of a link strength effect. We assume that, under the null hypothesis, these two effects do not influence the causal peer effect. Therefore, $m_{i}$ (which identifies the mode of selected peers) is exogenous, that is, uncorrelated with the disturbance term associated with the lying behavior, even in ENDO. Therefore, in the absence of a link strength effect, the lying behavior equations for an individual whose peers have chosen the Manual mode (eqs. (13") and (14)) should be the same in both EXO and ENDO. Thus, to jointly test the null hypothesis of no self-selection bias and no link strength effect, we can merely write the following general model that generalizes eq. $\left(13^{\prime \prime}\right)$ for both treatments, conditional on $m_{-i}=1$. Using an obvious notation, we obtain

$$
l_{i t}^{*}=\mathbf{x}_{i}^{\prime} \tilde{\boldsymbol{\theta}}+\theta_{1}\left(D_{E X O}\right) \bar{r}_{-i t}+\theta_{2}\left(D_{E N D O}\right) \bar{r}_{-i t}+\theta_{3} D_{E N D O}+\zeta_{i t},
$$

where $D_{E N D O}$ is a dummy variable that is equal to 0 for the EXO treatment and 1 for the ENDO treatment, $D_{E X O}=1-D_{E N D O}$, and where the $\theta$ s are parameters to be estimated. ${ }^{19}$ Under the null hypothesis of no self-selection bias in the peer effects and no link strength effect, $E(\boldsymbol{\zeta} \mid \cdot)=0$ and $\theta_{1}=\theta_{2} \cdot{ }^{20} \theta_{3}$ controls for the effect of ENDO on the intercept.

A simple strategy to evaluate the presence of self-selection or a link strength effect on peer effects comprises pooling the data of individuals who observed the performance of peers that chose the Manual mode and testing whether there is an additional effect associated with ENDO on lying. In other words, eq. (19) can be rewritten as

$$
l_{i t}^{*}=\mathbf{x}_{i}^{\prime} \tilde{\boldsymbol{\theta}}+\theta_{1} \bar{r}_{-i t}+\theta_{4}\left(D_{E N D O}\right) \bar{r}_{-i t}+\theta_{3} D_{E N D O}+\zeta_{i t},
$$

where $\theta_{4} \geq 0$ captures the presence of a self-selection bias in the peer effects or a link strength effect. Then, a one-tailed test of whether $\theta_{4}\left(=\theta_{2}-\theta_{1}\right)$ is 0 against the alternative hypothesis that it is larger than 0 is sufficient to determine whether the endogenous choice of peers affects the causal peer effects (a one-tailed test is sufficient because there is no reason to expect that $\theta_{2}<\theta_{1}$ ). This analysis leads to proposition 3 .

\footnotetext{
${ }^{19}$ Note that the performance of peers who chose the Automatic mode does not appear in this equation since we focus on the possible homophily bias in homogeneous networks, that is, when individuals who chose the Manual mode are matched with peers who also chose the Manual mode.

${ }^{20}$ For notational simplicity, we assume that ENDO does not impact the effects of the individuals' characteristics $\mathbf{x}_{\mathbf{i}}$ on their lying behavior, that is, the vector $\tilde{\boldsymbol{\theta}}$. This assumption is not rejected in our data analysis.
} 
Proposition 3 (Self-Selection Bias, Link Strength, and Causal Peer Effects) In ENDO, we assume that the selection of peers is homophilious (Proposition 2). The estimated effect of the average reported performance of peers who chose the Manual mode on individuals' lies may be biased upward because of self-selection or increased by a link strength effect generated by the selection of peers. Based on a comparison between estimates under EXO and ENDO, we can provide a joint test of the absence of both these features.

Proof: The absence of both a self-selection bias on peer effects and of a link strength effect can be jointly tested under the null hypothesis $\theta_{4}=0$ and $\mathbf{E}(\boldsymbol{\zeta} \mid \cdot)=\mathbf{0}$ in eq. (20) against the alternative hypothesis that $\theta_{4}>0$ or $\mathbf{E}(\boldsymbol{\zeta} \mid \cdot) \geq \mathbf{0}$ with at least one element strictly positive. ${ }^{21}$

\subsection{Procedures}

The experiment was conducted at GATE-Lab, Lyon, France. The 369 participants, mostly undergraduate students with majors in local engineering, business, and medicine, were recruited online using Hroot software (Bock et al., 2014). As indicated in Table A.1 in Appendix, we ran 16 sessions: four sessions with the Baseline $(N=72)$ and then six sessions with EXO $(N=143)$ and six sessions with ENDO $(N=154)$. EXO and ENDO requested more participants because the protocol generates four categories of participants instead of two in the Baseline because of the matching procedure. Table A.2 in Appendix reports statistics on their individual characteristics, by treatment.

Upon arrival, participants were assigned to a terminal after drawing a computer tag from an opaque bag. The instructions for each part were distributed at the beginning of each part and read aloud. Before starting the first part, participants had to fill out a comprehension questionnaire and practiced the task for two minutes. Avoiding deception was accomplished because we informed participants that their performance data (always kept anonymous) could be used in future sessions. At the end of the session, one period in each part was randomly drawn for payment. As pre-announced in the instructions to avoid the selection of a given pair of peers by pure curiosity, individuals who participated in EXO or ENDO received feedback on the mean performance in each of the five periods of the pair of peers they were not matched with in part 2. Finally, after they filled out a sociodemographic questionnaire, participants were paid in private in a separate room. On average, sessions lasted approximately 75 minutes. Participants earned on average 16.36 Euros (standard deviation $=3.73$ ), including a 5-Euro show-up fee.

\section{Results}

In this section we report our analysis of lying behavior by highlighting four points. ${ }^{22}$ First, we observed how individuals selected their mode of evaluation, and then, we characterized the extent to which they over-reported their performance before receiving any

\footnotetext{
${ }^{21}$ In the presentation of this proposition, we ignore for simplicity that the endogenous variable (individuals' lies) is left-censored. This is taken into account in the results section.

${ }^{22}$ We do not extensively discuss the actual performance in the text, because it is not the main aim of this study. The effects of explanatory variables on this outcome are very minor, as we explain next.
} 
social information. Second, we tested Proposition 1 by analyzing the effect of information on peers on lying behavior in EXO. Third, we tested Proposition 2 by exploring homophilious preferences in ENDO. Finally, we tested Proposition 3 by examining whether homophily influences the measurement of peer effects through self-selection bias and link strength. Because each individual played five periods in each part, the non-parametric statistics reported in this section are based on averaged measures per individual such that we consider one independent observation per individual in each part. Except if specified otherwise, the reported Mann-Whitney tests (MW, hereafter) are two-tailed.

\subsection{Mode Choice and Lying Behavior in Isolation}

Mode Choice- There is one observation per individual. $47.97 \%$ of the participants chose the Manual mode (43.06\% in the Baseline, $51.05 \%$ in EXO, and $47.40 \%$ in ENDO). None of the pairwise comparisons are significant ( $t$-tests, $p=0.270$ for EXO vs. Baseline, $p=0.543$ for ENDO vs. Baseline, and $p=0.532$ for ENDO vs. EXO), which was expected because part 1 was similar across treatments. Based on eqs. (7) and (8) of the model, Table A.3 in the Appendix displays the marginal effects of Probit regressions on the choice of the Manual mode, $M_{i}$. In model (1), the independent variables include individual characteristics; in model (2), we add EXO and ENDO dummies as regressors, as a sanitary test. No individual characteristics are significant at conventional levels (5\%) in any model, and there are no significant treatment effects. Therefore, the choice of the mode does not depend on observed individual characteristics.

Lying behavior in isolation (Part 1) - We now analyze performance and lies in part 1 in the three treatments, in which individuals were all performing the task in isolation. Our first result is the number of individuals who lied and by how much.

Result 1 (Mode Choice and Lying Behavior in Isolation) A small majority of people choosing the Manual mode over-reported their performance when they worked in isolation, and they very rarely maximized their earnings by lying.

Support for Result 1. Table 1 displays the percentage of participants who over-reported their performance at least once in part 1 and the percentage of "Manual-Dishonest" participants. Manual-Dishonest participants are defined as individuals whose average difference between the reported and actual performances in part 1 was higher than 1 per period, which allows for small calculation mistakes; otherwise, participants are classified as "Manual-Honest". Table 1 also summarizes the means and standard deviations of the actual performance, the reported performance, and the size of lies per individual and per period in part 1, according to the chosen mode and by treatment. In our analysis, we define a lie as any positive difference between actual and reported performance, but of course, some misreporting can occur because of mistakes. We estimate that the frequency of mistakes is very low. ${ }^{23}$

\footnotetext{
23 We can estimate the frequency of such mistakes by looking at the cases in which the actual performance was under-reported, - which, we assume, is not lying -, as mistakes should be symmetrical. Performance was under-reported in only 35 cases out of 1770 (1.98\% of the reports). In 19 under-reports the difference with the actual performance was equal to 1 ; in 12 under-reports it was equal to 2 and differences higher than 2 occurred only four times; the average size of under-reports was 1.71. These under-reports were present in any part, without significant differences across treatments. Since negative
} 
Table 1: Performance and Lies in Part 1, by Treatment

\begin{tabular}{lcccccccc}
\hline Treatment & \multicolumn{2}{c}{ Baseline } & \multicolumn{2}{c}{ EXO } & \multicolumn{2}{c}{ ENDO } & \multicolumn{2}{c}{ ALL } \\
\hline Chosen mode & Auto & Manual & Auto & Manual & Auto & Manual & Auto & Manual \\
\hline Actual & 12.87 & 13.79 & 14.46 & 12.76 & 13.25 & 13.21 & 13.61 & 13.12 \\
performance & $(3.60)$ & $(4.85)$ & $(3.56)$ & $(4.93)$ & $(3.17)$ & $(3.96)$ & $(3.45)$ & $(4.53)$ \\
Reported & - & 21.05 & - & 20.83 & - & 18.73 & - & 20.00 \\
performance & - & $(9.11)$ & - & $(8.38)$ & - & $(6.37)$ & & $(7.78)$ \\
\% Over-reporters & - & 61.29 & - & 65.75 & - & 67.12 & - & 65.54 \\
\% Manual-Dishonest & - & 51.61 & - & 53.42 & - & 52.05 & - & 52.54 \\
Mean size of lies & - & 7.26 & - & 8.08 & - & 5.51 & - & 6.88 \\
& & $(11.33)$ & - & $(10.80)$ & - & $(7.72)$ & & 9.76 \\
\hline N & 41 & 31 & 70 & 73 & 81 & 73 & 192 & 177 \\
Percentage & 56.94 & 43.06 & 48.95 & 51.05 & 52.60 & 47.40 & 52.03 & 47.97 \\
\hline
\end{tabular}

Notes: The table reports mean values and standard deviations in parentheses. "\% Over-reporters" corresponds to the extensive margin (percentage of participants who over-reported their performance at least once during part 1). "\% Manual-Dishonest" corresponds to the percentage of participants whose reports deviated from their actual performance by more than 1 on average per period. The mean size of lies in a period is the mean difference between the reported performance and the actual performance when participants chose the Manual mode. Performance is expressed as the number of points earned in a period. Auto for Automatic mode.

As shown in Table 1, not all participants who chose the Manual mode lied. Overall, $65.54 \%$ over-reported their performance at least once during this part: $61.29 \%$ in the Baseline, $65.75 \%$ in EXO, and $67.12 \%$ in ENDO. None of the pairwise comparisons are significant in $t$-tests $(p=0.667$ for EXO vs. Baseline, $p=0.572$ for ENDO vs. Baseline, and $p=0.862$ for ENDO vs. EXO). We classify $52.54 \%$ of the participants who chose the Manual mode as Manual-Dishonest participants overall (51.61\% in the Baseline, $53.42 \%$ in EXO, and $52.05 \%$ in ENDO).${ }^{24}$ None of the pairwise comparisons are significant in $t$-tests $(p=0.867$ for EXO vs. Baseline, $p=0.967$ for ENDO vs. Baseline, and $p=0.869$ for ENDO vs. EXO). That at least $34.46 \%$ of the participants who chose the Manual mode did not lie reveals that the cognitive cost of having to calculate one's performance was compensated by some non-pecuniary benefits. ${ }^{25}$

Our model assumes that the actual performance is always strictly positive $\left(p_{i t}>0\right)$; thus, individuals in the Manual mode should lie only partially. This assumption is what we found. A very small minority of participants lied to the full extent: in part 1, five individuals $(2.82 \%)$ reported 40 points in each period (corresponding to 20 grids paid at the highest piece rate of 2 points), and five decisions (from different individuals) corresponded to the maximum possible lie (reporting 40 when the actual performance

mistakes were rare and small in magnitude, we can conclude that the vast majority of over-reports were intentional lies and not mistakes. Nevertheless, in order to account for these mistakes, we defined a participant as Dishonest if the size of his lies per period in part 1 was greater than 1 on average.

${ }^{24}$ In our analysis of peer effects, we also explored a stricter definition of liars, in which individuals were categorized as Manual-Dishonest if their average lie size in part 1 was higher than 2 (see next).

${ }^{25}$ The reasons mentioned in a post-experimental questionnaire by individuals who chose the Manual mode but did not lie were that they wanted to have more control on their earnings, they preferred to calculate themselves, or they were willing to test their honesty (which shows that people understood that they could lie with this mode). Another possible related reason is signaling their honesty to the experimenter by exposing themselves to a context where lying was possible and not lying. 
was 0 ). When people over-reported their performance, on average, they inflated it by $52.44 \%$ overall (average actual performance: 13.12 and average lie size: 6.88 ), by $52.65 \%$ in the Baseline, by $63.33 \%$ in EXO, and by $41.71 \%$ in ENDO. If we restrict our scope to the Manual-Dishonest individuals, on average, they inflated their performance by $113 \%$ overall (average actual performance: 11.50 and average lie size: 13.02), by $115 \%$ in the Baseline, by $135 \%$ in EXO, and by $91 \%$ in ENDO. More generally, none of the differences across treatments in Table 1 are significant, except that the actual performance of participants who chose the Automatic mode is higher in EXO than in the other treatments (MW, EXO vs. Baseline, $p=0.041$, and EXO vs. ENDO, $p=0.021$ ).

We next checked whether our separability assumption holds in the data. Notably, if we pool the treatments, the average actual performance is not significantly different for the participants who chose the Manual mode and for those who chose the Automatic mode (MW test, $p=0.798$ ). This is also true if we consider each treatment separately, except for EXO, in which participants who chose the Automatic mode performed marginally significantly better than those who chose the Manual mode (MW test, $p=0.072$ ). However, if we only consider the Manual-Dishonest participants, there is a significant difference in the actual performance with the participants who chose the Automatic mode (MW tests, $p=0.002$ ), suggesting that for these people lying partially substituted for effort. However, most of the time, their actual performance was far from 0 (it was equal to 0 in only $4.3 \%$ of the observations) (see Figure A.5 in Appendix).

Finally, we estimated eqs. (5) and (6) to analyze the impact of demographic variables on the size of lies when participants who chose the Manual mode were isolated. Table A.4 in Appendix displays the marginal effects of random-effect (RE) Tobit regressions in which the dependent variable is the (latent) size of lies in each of the five periods of part $1 .{ }^{26}$ Although the estimators of the RE Tobit model may be subject to a selection bias, the regressions on the mode choice reported in Table A.3 in Appendix suggest that it is not likely to be the case, because no (observable) demographic variables are significant at the $5 \%$ level.

\subsection{Peer Effects on Lying Behavior}

We now consider part 2. Descriptive statistics on actual performance, reported performance, and size of lies are summarized in Table A.5 in Appendix. According to Proposition 1, the size of an individual's lies is not affected by the average actual performance of peers who chose the Automatic mode and thus could not lie, but it can be influenced by the average reported performance of peers who chose the Manual mode (taken as an approximation of their expected lies; eqs. (13) and (14)). To test this proposition, we study the effects of peers' performance on the size of lies, controlling for individual characteristics, in EXO, where a self-selection bias can be ruled out by design. We analyze peer effects in ENDO in section 4.4, in which we address the question of a possible self-selection bias generated by homophily. ${ }^{27}$ Our second result supports

\footnotetext{
${ }^{26}$ As well known, the fixed effect Tobit is inconsistent due to the incidental parameter problem. In the RE Tobit model, the composite disturbance term is given by $\mu_{i t}=\gamma_{i}+\xi_{i t}$, where $\gamma_{i}$ is an individualspecific error with $\gamma_{i} \sim N\left(0, \sigma_{\gamma}^{2}\right)$, and $\xi_{i t}$ is a random term with $\xi_{i t} \sim N\left(0, \sigma_{\xi}^{2}\right)$. The model is estimated using a maximum likelihood approach.

${ }^{27}$ In our econometric model, the expected size of lies is the product of the probability of lying (extensive margin) and the (expected) size of lies conditional on lying (intensive margin). One could estimate
} 
Proposition 1 and is summarized as follows:

Result 2 (Peer Effects on Lying) In EXO, the size of lies of individuals who chose the Manual mode was not affected by the performance of peers who selected the Automatic mode, whereas it increased with a higher reported performance of peers that selected the Manual mode. Such conformity with this category of peers was found among individuals who were lying in part 1 (Manual-Dishonest individuals) but not among those who did not lie in part 1 (Manual-Honest individuals).

Support for Result 2. Table 2 displays the marginal effects of RE Tobit regressions in which the dependent variable is the size of lies in each period of part 2 , conditional on choosing the Manual mode. Model (1) in Table 2 pools the participants from EXO who selected the Manual mode and provides estimates of eq. (13) augmented for Auto peers' actual performance. From eqs. $\left(13^{\prime}\right)$ and $\left(13^{\prime \prime}\right)$, one easily shows that this model also imposes the restriction that the marginal effects of individual characteristics are not affected by the mode chosen by peers (that is, $\lambda_{4}=\lambda_{6}$, which is tested next). Model (2) (respectively, model (3)) is estimated based on participants who selected the Manual mode and were matched with peers who chose the Automatic mode (respectively, peers who chose the Manual mode). Thus, models (2) and (3) allowed us to test eqs. (13') and $\left(13^{\prime \prime}\right)$. Models (4) and (5) also consider participants who selected the Manual mode and were matched with peers who made the same choice, but they are estimated based on the sub-samples of Manual-Honest participants ("Manual-H" in the Table) and ManualDishonest participants ("Manual-D"), respectively, as defined by their behavior in part 1. The most important independent variable is the actual or reported performance of peers, according to their chosen mode. These regressions control for the participants' individual characteristics; none of them are significant at standard levels ( $\leqslant 5 \%$ level).

Consistent with the first part of Proposition 1, in models (1) and (2), the participants' size of lies is not influenced by their peers' actual performance under the Automatic mode. By contrast, and consistent with the second part of Proposition 1, the higher the observed reported performance from peers who chose the Manual mode, the higher the participants' size of lies (see models (1), (3), and (5)). This significant effect is clear evidence of positive peer effects on dishonesty. ${ }^{28}$ Moreover, the magnitude of these peer effects is not small. Notably, an increase of 1 earnings point by peers increased an individual's lies by 0.194 points in EXO (model (1)). The impact is stronger if we focus on the individuals matched with peers who chose the Manual mode (model (3)), and even stronger when the individual was dishonest in part 1 (the increase amounts to 0.432 points in model (5)).

Notably, the effect of peers vanished when we restricted our scope to the ManualHonest participants: in model (4), peers' performance is not significant. ${ }^{29}$ In EXO, only

various peer effects at both margins (see McDonald and Moffitt, 1980, for the formulas in the standard Tobit). For the sake of concision, we focus only on the product of both margins, that is, on marginal effects. In the Tobit model, the sign of the effect of a regressor at both margins is the same.

${ }^{28}$ Note that individuals did not necessarily lie to equalize their reported performance to that of their peers. Equalizing performance represented only $4.18 \%$ of the observations. Participants reported less than their peers' average performance in $52.09 \%$ of the observations, and more in $43.74 \%$ of the observations (in EXO, they reported less (more) than their peers in $46.32 \%(49.47 \%$ ) of the observations and in ENDO, they reported less (more) than their peers in $56.23 \%$ (39.62\%) of the observations.

${ }^{29}$ As a robustness test, we replicated Table 2 with a stricter definition of Manual-Dishonest partici- 
Table 2: Peer Effects on the Size of Lies under the Manual Mode, EXO Treatment (Part 2)

\begin{tabular}{lccccc}
\hline \hline $\begin{array}{l}\text { Dep. var.: } \\
\text { Size of lies }\end{array}$ & (1) Manual & $\begin{array}{c}\text { (2) Manual } \\
\text { Auto peers }\end{array}$ & $\begin{array}{c}\text { (3) Manual } \\
\text { Manual peers }\end{array}$ & $\begin{array}{c}\text { (4) Manual-H } \\
\text { Manual peers }\end{array}$ & $\begin{array}{c}\text { (5) Manual-D } \\
\text { Manual peers }\end{array}$ \\
\hline (AUTO) Peers & -0.005 & -0.062 & - & - & - \\
actual perf. & $(0.123)$ & $(0.110)$ & - & - & - \\
(MANUAL) Peers' & $0.194^{* *}$ & - & $0.229^{*}$ & -0.146 & $0.432^{* * *}$ \\
reported perf. & $(0.076)$ & - & $(0.117)$ & $(0.151)$ & $(0.153)$ \\
\hline $\begin{array}{l}\text { Individual } \\
\text { characteristics }\end{array}$ & $Y e s$ & $Y e s$ & $Y e s$ & Yes & Yes \\
\hline Nobs. & 365 & 175 & 190 & 65 & 125 \\
Left-censored obs. & 144 & 87 & 57 & 50 & 7 \\
Log-likelihood & -761.18 & -297.83 & -458.46 & -62.60 & -376.97 \\
\hline $\begin{array}{l}\text { Log-likelihood test } \\
\lambda_{4}=\lambda_{6} \text { (p-value) }\end{array}$ & $0.00214^{* * *}$ & & & & \\
\hline \hline
\end{tabular}

Notes: This table reports the marginal effects from RE Tobit regressions with standard errors in parentheses. The dependent variable is the size of lies in each period of part 2 in EXO. There are 5 observations per individual. The marginal effects are calculated as the average marginal effects over time and over individuals. (AUTO) Peers' actual performance is the average actual performance observed in the period from the two peers who chose the Automatic mode. (MANUAL) Peers' reported performance is the average reported performance observed in the period from the two peers who chose the Manual mode (its coefficient is the marginal effect corresponding to $\lambda_{6}(1-$ $\delta) /\left(1+\lambda_{6}\right)$ in our model). The individual characteristics include the participant's age in years, gender, educational achievement (from 0 to 9 ), student status, being a student in business, monthly expenses, and a binary variable for a first participation in an economic experiment. Models with Manual participants include all the participants who chose the Manual mode, while models with Manual- $H$ or Manual-D, respectively, include only the participants who were classified as honest or dishonest in part 1. Models with Auto peers (Manual peers, respectively) include only the participants who were matched with peers who chose the Automatic (Manual) mode. ${ }^{* *} p<0.05$ *** $\quad p<0.01$. 
five participants that selected the Manual mode (around $7 \%$ of the Manual participants) switched from the Manual-Honest category to the Manual-Dishonest category between part 1 and part 2, that is, their average size of lies per period became greater than 1 in part 2. Moreover, the average size of lies in part 2 of these switchers was quite low: they inflated their performance by 6.04 points per period on average while ManualDishonest participants inflated their performance by 19.63 points on average, showing that most of them remained fundamentally honest despite the information received. ${ }^{30} 31$

Finally, we tested model (1), which implies that the marginal effects of individual characteristics are not affected by the mode chosen by peers (that is, $\lambda_{4}=\lambda_{6}$ ). We performed this test by comparing models (2) and (3) with model (1) (which imposes this equality), using a log-likelihood test (see Table 2$)$. This equality is rejected at the $1 \%$ level $(p$-value $=0.002)$. Therefore, model $(1)$ is rejected, which justifies to estimate models (2) and (3) separately.

\subsection{Homophily in the Choice of Peers}

We now consider homophily in terms of the mode chosen. According to Proposition 2, in ENDO, individuals prefer to be matched with participants who chose the same mode as the individuals did (a), and homophily is stronger for individuals who misreported their performance when working in isolation (b). Our results support (b) and partially support (a):

Result 3 (Preference for Homophily) Homophily in the choice of peers characterizes participants who selected the Manual mode and lied in part 1. Individuals who chose the Automatic mode or chose the Manual mode but did not lie do not exhibit preferences for homophily.

Support for Result 3. In ENDO, $57.79 \%$ of the participants selected peers who chose the Manual mode. This percentage differs across participants by their chosen mode and their behavior in part 1 (Figure 2). 55.55\% of the participants who chose the Automatic mode selected peers who made the same choice. This percentage is not significantly different from $50 \%$ (binomial test, $p=0.374$ ), which rejects homophily based on the mode chosen. By contrast, $72.60 \%$ of the participants who chose the Manual mode selected peers that also chose the Manual mode. If among this group we consider only those who over-reported their performance in isolation (Manual-Dishonest participants), this percentage is even larger $(81.58 \%)$; it is $62.86 \%$ for those who chose the Manual mode

pants. In Table A.6 in the Appendix, an individual was classified as Manual-Dishonest if he reported on average more than 2 more points than his actual performance per period in part 1 (instead of more than 1 in Table 2), and as Manual-Honest otherwise. The results remained qualitatively similar.

${ }^{30}$ In ENDO, we found qualitatively the same results: only eight participants switched from the Manual-Honest category to the Manual-Dishonest category, and the switchers inflated their performance by 3.5 points on average per period, while Manual-D participants inflated their performance by 17.94 points.

${ }^{31}$ We also analyzed the influence of peers' performance on the participants' actual performance according to the chosen mode, using the same models as those of Table 2 but in which the dependent variable was the individual's actual performance in each period. Table A.8 in Appendix reveals that peers' actual or reported performance had no significant influence on the performance of participants who chose the Automatic mode in any treatment. Table A.9 in the Appendix delivers the same conclusion for participants who chose the Manual mode. Peer effects influenced lying but not actual effort. 
but did not lie in part 1 (Manual-Honest participants). The percentage is significantly higher than a random choice of peers for Manual-Dishonest (binomial test, $p<0.001$ ), but not for Manual-Honest participants $(p=0.175) .{ }^{32}$ This finding reveals that only those who lied in isolation exhibited a preference for homophily, and they were willing to link with individuals who were likely to behave as they would.

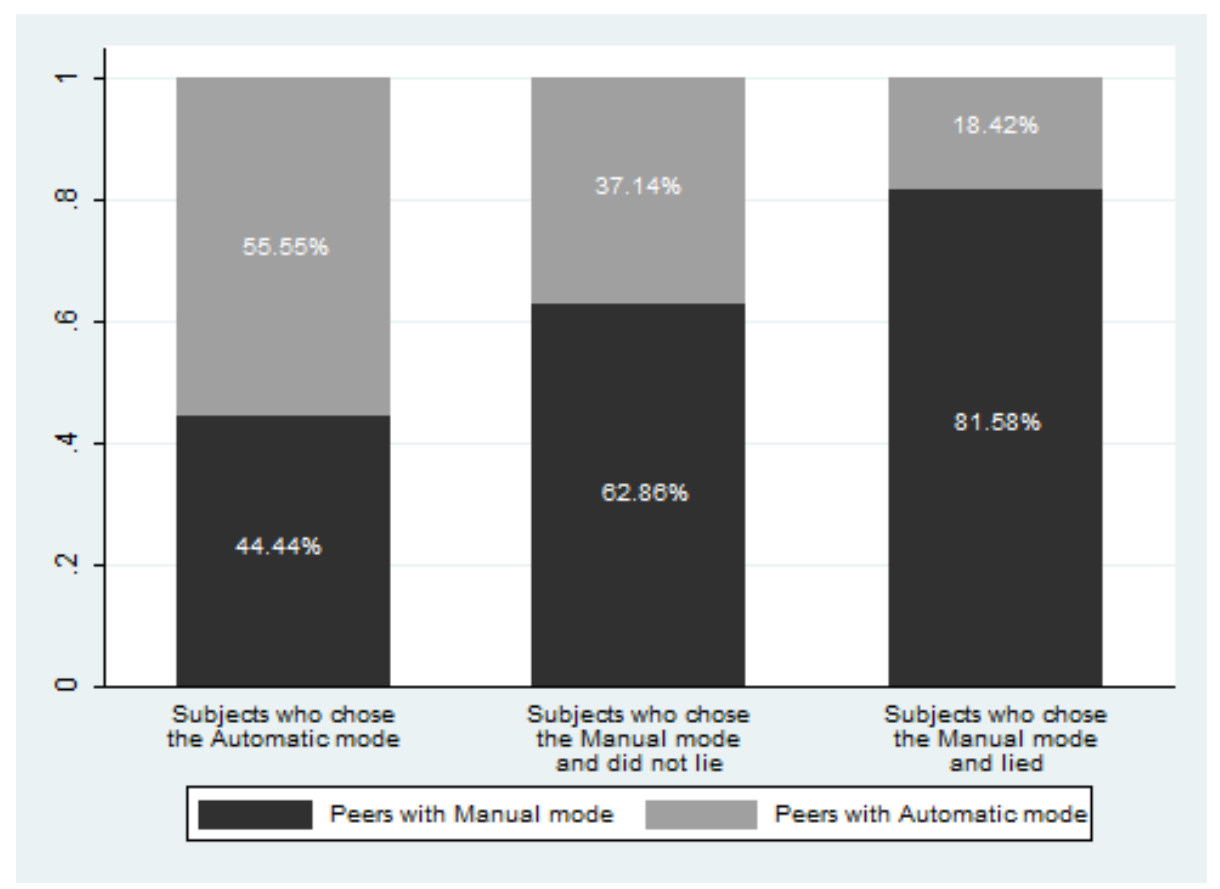

Figure 2: Choice of Peers According to the Chosen Mode and Lying Behavior in Part 1

Notes. The figure displays the share of peers with their mode of evaluation for three categories of participants in ENDO: participants who selected the Automatic mode (left bar), participants who selected the Manual mode but did not lie in part 1 (Manual-Honest, middle bar), and participants who selected the Manual mode and lied in part 1 (Manual-Dishonest, right bar).

Table 3 provides parametric tests based on our homophily utility model (eqs.(15)(18)), using a linear probability approach. Ordinary Least Square (OLS) regressions were performed for all (pooled) participants (models (1) and (2)), and for those who chose the Automatic mode (model (3)), or the Manual mode (model (4)), separately; the latter were also decomposed into Manual-Honest (model (5)) and Manual-Dishonest participants (model (6)). The dependent variable is a dummy variable equal to 1 when the participant selected a pair of peers that chose the same mode as him, and 0 otherwise.

\footnotetext{
${ }^{32}$ None of the binomial tests were significant in EXO, showing that randomization worked properly.
} 


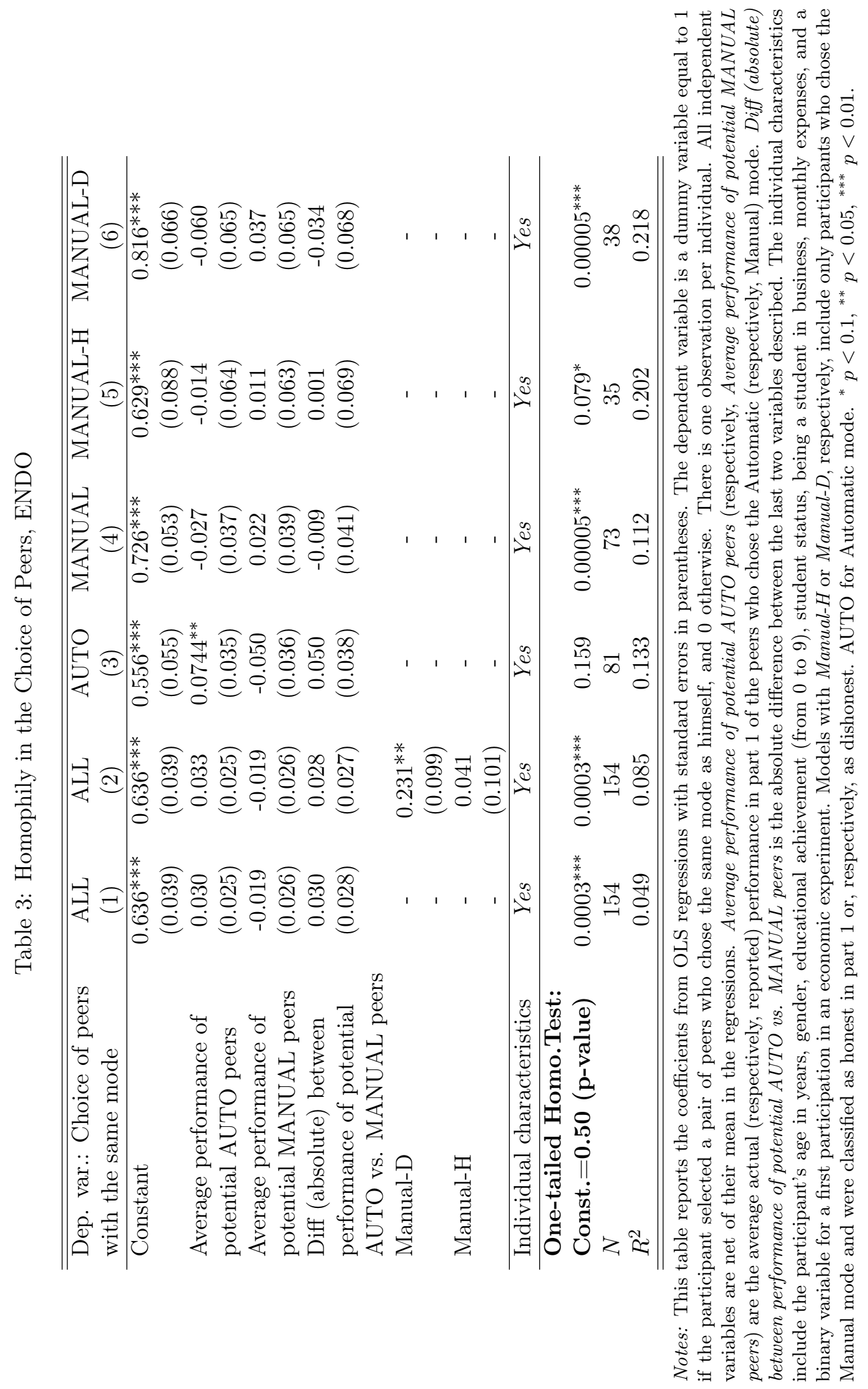


The independent variables include the information provided to the participants before they made their choice of peers, namely, the average actual performance $\left(P_{i}^{A}\right.$ in the theoretical model $)$ and reported performance $\left(P_{i}^{M}\right.$ in the theoretical model $)$ in part 1 of the two pairs of peers that were presented to the participant. We also include the absolute difference between these two variables. We control for the same individual characteristics as in Table 2; only the variable Student is significant at the $5 \%$ level and positive in models (4) and (5). The observable characteristics are net of their mean; thus, the constant can be interpreted as an estimator of the average proportion of participants who prefer to be matched with similar peers. Notably, the values of the constant closely correspond to the numbers reported in Fig. 2.

We performed one-tailed tests where the null hypothesis is $H_{0}:$ Constant $=0.50$ (no homophily), and the alternative hypothesis is $H_{A}:$ Constant $>0.5$ (homophily). Our tests indicate the presence of homophily for the whole population and for the participants who chose the Manual mode (models (1) and (4)). Homophily is rejected for those who chose the Automatic mode (model (3)). Model (2) indicates that Manual-Dishonest individuals were more likely to exhibit homophilious preferences than those who chose the Automatic mode are, and the Manual-Honest participants do not differ from the latter. Similar tests performed separately on honest and on dishonest participants, reject homophily at the $5 \%$ level for Manual-Honest participants $(p=0.079$, model $(5))$ but not for Manual-Dishonest participants $(p<0.0001$, model $(6))$.

Homophily characterizes individuals with a weaker moral type. This may result from a preference for similarity or for a reference group that signals a weak empirical social norm, thus providing a self-excuse for cheating. By contrast, homophily is rejected for both the participants who chose the Automatic mode and those who chose the Manual mode but did not lie. When selecting their peers, these individuals were indifferent to the peers' performance and chosen mode. The responses to our post-experimental questionnaire indicate that for some of them, the choice was nevertheless strategic: expecting to observe a high performance from peers who chose the Manual mode (even artificially inflated) was reported as a source of motivation for performing the task.

\subsection{Impact of Homophily on the Measure of Peer Effects}

We now test Proposition 3 by checking the presence of a self-selection bias because of the homophily we just observed, or of a link strength effect in ENDO. If present, both the self-selection bias and the link strength effect would inflate the size of peer effects in this treatment, compared with those measured in EXO in subsection 4.2. Using a joint test on participants who chose the Manual mode and selected peers who made the same choice, we show that peer effects are of the same magnitude in EXO and ENDO. This analysis does not reject Proposition 3; thus, we conclude that homophily did not result in bias and did not inflate our estimates of peer effects.

Result 4 (Selection Bias, Link Strength, and Causal Peer Effects) In ENDO, we jointly reject the presence of a selection bias and of a link strength effect because of homophily in the measure of peer effects.

Support for Result 4. Following eq.(20), we pooled the samples from the two treatments. Next, we regressed the size of lies on the average reported performance of peers in EXO 
and ENDO, and added as regressors the average reported performance of peers in ENDO and a dummy variable $\left(D_{E N D O}\right)$ for ENDO while controlling for the usual individual characteristics. ${ }^{33}$ Only the First participation variable is significant at the $1 \%$ level and negative in model (1). Table 4 reports the results by using a RE Tobit model.

Table 4: Impact of Endogenous Matching on the Estimated Peer Effects on the Size of Lies

\begin{tabular}{lccc}
\hline \hline Dependent Variable: & MANUAL-ALL & MANUAL-H & MANUAL-D \\
Size of lies & $(1)$ & $(2)$ & $(3)$ \\
\hline (MANUAL) Peers' Reported & $0.191^{* * *}$ & 0.008 & $0.201^{* *}$ \\
Performance & $(0.061)$ & $(0.023)$ & $(0.093)$ \\
(MANUAL) Peers' Reported & 0.006 & -0.018 & 0.068 \\
Performance $\times D_{E N D O}$ & $(0.088)$ & $(0.034)$ & $(0.144)$ \\
$D_{E N D O}$ & -1.444 & -0.005 & -4.728 \\
& $(2.197)$ & $(0.670)$ & $(3.557)$ \\
\hline Individual characteristics & $Y e s$ & $Y e s$ & $Y e s$ \\
\hline$N$ & 730 & 345 & 385 \\
Left-censored & 292 & 275 & 17 \\
Log-likelihood & -1487.10 & -282.11 & -1135.11 \\
\hline \hline
\end{tabular}

Notes: The table reports the marginal effects from RE Tobit regressions on EXO and ENDO. The marginal effects are calculated as the average marginal effects over time and over individuals. Standard errors are in parentheses. The dependent variable is the size of lies in each period of part 2. There are five observations per individual. (MANUAL) Peers' Reported performance is the average reported performance observed in the period from the two peers who chose the Manual mode. $D_{E N D O}$ is a dummy variable equal to 1 if the treatment is ENDO, and to 0 if it is EXO. The individual characteristics include the participant's age in years, gender, educational achievement (from 0 to 9 ), student status, being a student in business, monthly expenses, and a binary variable for a first participation in an economic experiment. Model (1) includes all the participants who chose the Manual mode; models (2) and (3) include only the participants who chose the Manual mode and were honest in part 1 or, respectively, dishonest. ${ }^{* *} \mathrm{p}<0.05^{* * *} \mathrm{p}<0.01$.

Model (1) in Table 4 confirms that the marginal effect of the performance of peers who chose the Manual mode is positive and highly significant. On average, in the pooled EXO and ENDO an increase of 1 earnings point reported by peers in a period increased the lies of participants by 0.191 earnings points. The coefficient of the (MANUAL) Peers' Reported Performance $\times D_{E N D O}$ variable is positive but not significant (and small). This one-tail test jointly rejects the hypothesis that homophily generated self-selection bias or a link strength effect that would affect the size of peer effects in ENDO but not in EXO. The dummy variable $\left(D_{E N D O}\right)$ is not significant, indicating that ENDO had no effect per se on the size of lies. However, homophily was found only for the participants who chose the Manual mode and lied in part 1 . Thus, we re-estimated model (1) separately for the Manual-Honest (model (2)) and the Manual-Dishonest participants (model (3)). ${ }^{34}$ Table 4 confirms Result 2 that peer effects

\footnotetext{
${ }^{33}$ Allowing the coefficients of these characteristics to be different in ENDO does not qualitatively change the results of the tests.

${ }^{34}$ As a robustness test, we replicated Table 4 with a stricter definition of Manual-Dishonest participants. In Table A.7 in the Appendix, an individual was classified as Manual-Dishonest if he reported on average more than 2 more points than his actual performance per period in part 1 (instead of more than 1 point in Table 4), and as Manual-Honest otherwise. The results remained qualitatively similar.
} 
are not significant for the Manual-Honest participants but significant and strong for the Manual-Dishonest participants; it also shows that for the latter category, peer effects are equal in EXO and ENDO, confirming the finding of model (1).

\section{Discussion and Conclusion}

In real settings, the estimation of peer effects is often blurred because individuals may behave similarly to their peers partly because similar individuals tend to link together. In the extreme, peers could have the same behavior even in the absence of any interindividual influence, simply because of homophilious matching. If information on how social networks are formed is not available, the estimates of peer effects may be severely biased because of a self-selection problem. A laboratory setting allows researchers to observe perfectly the formation of links and individuals' information on their peers. Through relevant treatment manipulations, it can help identify separately the effect of the endogenous choice of peers and the effect of peers' behavior on individuals' decisions motivated by conformity. This was precisely the aim of this study.

Our study delivers four main findings. First, not all individuals lied even after choosing an environment in which the main advantage was that over-reporting their performance to earn more was allowed. Second, individuals' lying behavior was not influenced by the actual performance of peers who chose a setting that forbids lying; by contrast, it was influenced by the reports of peers who chose a setting that allowed lying, but this was the case only among individuals who lied when working in isolation. Individuals who reported honestly in isolation were not influenced by their peers' reported performance. This suggests the presence of heterogeneity in peers effects. Third, we provided evidence of homophily but again, only among liars. When liars had to create their links, they were more likely to match with peers who chose the evaluation mode that allowed them to cheat. Four, our analysis rejected that homophily biased the measure of conformity and that endogenous matching generated a link strength effect, because peer effects were not significantly higher when individuals could select their peers.

Our first result complements the previous experimental literature that has shown that not all people lie. By contrast with this literature we consider a setting in which individuals could choose their cheating opportunities (for a recent exception, see Konrad et al. (2021)). Here, an interpretation is that individuals with a strong moral type may be indifferent to the opportunities provided by the more flexible environment when they are confident in their ability to surrender temptation; for some people, choosing a setting that allows them to lie and not lying may be motivated by the willingness to signal a strong moral type. Consistently, when matching was exogenous, honest individuals were not influenced by the reported performance of peers who might be cheating. Thus, it may not be surprising that their matching choices were not homophilious when they could select their peers. They did not necessarily search for similar peers, and they did not reject likely cheaters.

By contrast, the individuals who had revealed a weak moral type by lying in isolation were influenced by peers who chose the same mode. Conformity with peers could be a source of hedonic utility by allowing individuals to believe that they were complying 
with a social norm. Consistently, a higher share of these individuals was willing to be matched with similar peers. One interpretation of this is that it provided willful ignorance of good examples and created a reference group signaling a less virtuous social norm. That liars were more likely to exhibit homophilious preferences than non-liars was also observed by Flashman and Gambetta (2014), but for a reason related to trust and mutual obligations. Here, the mechanism is probably more related to selective norm compliance. Because information on peers' performance was also information on peers' payoffs, another potential reason for peer effects and homophily could be that individuals were inequality averse. However, there is no evidence that inequality aversion is what motivated lying, because individuals who were more prone to peer effects and homophily were those who lied in isolation, when no social comparisons were available.

Our fourth finding - the absence of a severe self-selection bias because of homophily - contrasts with some of the papers that have suggested that endogeneity in network formation is a source of bias in the peer effects estimator (e.g., see Carrell et al., 2013; Hsieh et al., 2020). However, this finding is consistent with those of other studies, especially those using observational data from Add Health (e.g., see Goldsmith-Pinkham and Imbens, 2013; Boucher, 2016; Badev, Forthcoming) that found a weak effect of network endogeneity on this estimator. As long as there is some external validity in our experiment, our analysis suggests that self-selection because of homophily is not likely to be an important source of bias on the estimation of conformity effects when using observational data to study dishonest behavior.

This study has limitations, and we suggest four directions for further research. First, we studied conformity effects in the absence of synergy between players. A notable extension would be to introduce incentive schemes in which payoffs also depend on the performance of peers, because the nature of incentives might affect how criminals select their partners in crime. Homophily may be motivated by instrumental reasons in addition to hedonic reasons. Thus, a notable investigation would be of the extent to which conformity effects differ from the effects of strategic complementarities, and whether homophily affects these peer effects differently. Second, we interpreted the homophilious selection of peers by individuals with a weak moral type as the choice of a convenient signal for a prevailing lenient norm. However, we did not elicit the players' beliefs on the size of lies of their peers (to avoid experimenter demand effects), and we did not test directly whether social information influenced the perceived social norm. Further research could directly measure the impact of homophily on the perceived norm. Third, in our study, social information was on peers' performance. However, in real settings, individuals are exposed to various types of information, including others' characteristics or judgments. Thus, further research could explore peer effects and homophily when social information is one of these other types of information. Finally, in our study, participants' decisions were not observable by other players. Introducing observability to measure how this would affect the size of peer effects and homophily would be another notable extension. 


\section{References}

Abeler, J., D. Nosenzo, And C. Raymond (2019): "Preferences for truth-telling," Econometrica, 87, 1115-1153.

Akerlof, G. A. and R. E. Kranton (2000): "Economics and identity," The Quarterly Journal of Economics, 115, 715-753.

Angrist, J. (2014): "The perils of peer effects," Labour Economics, 30, 98 - 108.

Aral, S. And D. Walker (2014): "Tie Strength, Embeddedness, and Social Influence: A Large-Scale Networked Experiment," Management Science, 60, 1352-1370.

BADEv, A. (Forthcoming): "Nash equilibria on (un)stable networks," Econometrica.

Bäker, A. And M. Mechtel (2019): "the Impact of Peer Presence on Cheating," Economic Inquiry, 57, 792-812.

Ballester, C., A. Calvo-Armengol, And Y. Zenou (2006): "Who's Who in Networks. Wanted: The Key Player," Econometrica, 74, 1403-1417.

Benhabib, J., A. Bisin, And M. O. Jackson (2010): The Handbook of Social Economics, vol. 1A and 1B, Amsterdam: North Holland.

BiCCHieri, C. (2012): The Grammar of Society - The Nature and Dynamics of Social Norms, Cambridge University Press, Cambridge.

Bicchieri, C., E. Dimant, S. GÄchter, And D. Nosenzo (2019): "Social Proximity and the Erosion of Norm Compliance," https://ssrn.com/abstract = or http://dx.doi.org/10.2139/ssrn.3355028.

Bock, O., I. Baetge, And A. Nicklisch (2014): "hroot: Hamburg registration and organization online tool," European Economic Review, 71, 117-120.

Boucher, V. (2016): "Conformism and self-selection in social networks," Journal of Public Economics, 136, 30-44.

Boucher, V. And B. Fortin (2016): "Some challenges in the empirics of the effects of networks," in The Oxford Handbook of the Economics of Networks, ed. by Y. Bramoullé, A. Galeotti, and B. Rogers, Oxford University Press, chap. 12, 277302.

Bramoullé, Y., H. Djebbari, And B. Fortin (2020): "Peer effects in networks: a survey," Annual Review of Economics, 12, 603-629.

Bramoullé, Y., R. Kranton, and M. D'Amours (2014): "Strategic interaction and networks," American Economic Review, 104, 898-930.

Calvó-Armengol, A., E. Patacchini, and Y. Zenou (2009): "Peer effects and social networks in education," The Review of Economic Studies, 76, 1239-1267.

Carrell, S. E., F. V. Malmstrom, And J. E. West (2008): "Peer effects in academic cheating," Journal of Human Resources, 43, 173-207. 
Carrell, S. E., B. I. Sacerdote, and J. E. West (2013): "From natural variation to optimal policy? The importance of endogenous peer group formation," Econometrica, 81, 855-882.

Currarini, S., M. O. Jackson, and P. Pin (2009): "An economic model of friendship: Homophily, minorities, and segregation," Econometrica, 77, 1003-1045.

Currarini, S. And F. Mengel (2016): "Identity, homophily and in-group bias," European Economic Review, 90, 40-55.

Damm, A. And C. Dustmann (2014): "Does growing up in a high crime neighborhood affect youth criminal behavior?" American Economic Review, 104, 1806-1832.

DE PAula, (2017): "Econometrics of network models," in Advances in Economics and Econometrics: Eleventh World Congress, ed. by B. Honoré, A. Pakes, M. Piazzesi, and L. Samuelson, Cambridge University Press, vol. 1, 268-323.

Diekmann, A. W., W. Przepiorka, And H. Rauhut (2015): "Lifting the veil of ignorance: An experiment on the contagiousness of norm violations," Rationality and Society, 27, 309-333.

Drago, F., F. Mengel, and C. Traxler (2020): "Compliance Behavior in Networks: Evidence from a Field Experiment," American Economic Journal: Applied Economics, $12,96-133$.

Dufwenberg, M. and M. A. Dufwenberg (2018): "Lies in disguise - A theoretical analysis of cheating," Journal of Economic Theory, 175, 248 - 264.

Díaz, C. And E. Patacchini (2020): "Parents, Neighbors and Youth Crime," IZA Discussion Paper.

Efferson, C., R. Lalive, and E. Fehr (2008): "The coevolution of cultural groups and ingroup favoritism," Science, 321, 1844-1849.

Egan, M., G. Matvos, And A. Seru (2019): "The Market for Financial Adviser Misconduct," Journal of Political Economy, 127, 233-295.

Falk, A., D. Huffman, And K. Mierendorff (2006): "Incentive effects and political acceptability of workfare," Institute for the Study of Labour (IZA).

Fischbacher, U. AND F. Föllmi-Heusi (2013): "Lies in disguise - an experimental study on cheating," Journal of the European Economic Association, 11, 525-547.

Flashman, J. And D. Gambetta (2014): "Thick as thieves: Homophily and trust among deviants," Rationality and Society, 26, 3-45.

Fortin, B., G. Lacroix, And M. C. Villeval (2007): "Tax evasion and social interactions," Journal of Public Economics, 91, 2089-2112.

Fosgaard, T. R., L. G. Hansen, And M. Piovesan (2013): "Separating will from grace: an experiment on conformity and awareness in cheating," Journal of Economic Behavior \& Organization, 93, 279-284. 
Gavrilova, E. (2019): "A partner in crime: Assortative matching and bias in the crime market," Journal of Economic Behavior \& Organization, 159(C), 598-612.

Gino, F., S. Ayal, And D. Ariely (2009): "Contagion and differentiation in unethical behavior: The effect of one bad apple on the barrel," Psychological science, 20, 393398.

Glaeser, E. L., B. Sacerdote, and J. A. Scheinkman (1996): "Crime and social interactions," The Quarterly Journal of Economics, 111, 507-548.

Gneezy, U., A. Kajackaite, And J. Sobel (2018): "Lying Aversion and the Size of the Lie," American Economic Review, 108, 419-53.

Goldsmith-Pinkham, P. And G. W. Imbens (2013): "Social networks and the identification of peer effects," Journal of Business 85 Economic Statistics, 31, 253-264.

GoluB, B. AND M. O. JACKSON (2012): "How homophily affects the speed of learning and best-response dynamics," The Quarterly Journal of Economics, 127, 1287-1338.

Graham, B. S. (2019): "Network data," Tech. rep., National Bureau of Economic Research.

Gross, J., M. Leib, T. Offerman, And S. Shalvi (2018): "Ethical free riding: when honest people find dishonest partners," Psychological Science, 1956-1968.

HaYnie, D. L. (2001): "Delinquent peers revisited: Does network structure matter?" American Journal of Sociology, 106, 1013-1057.

Henrich, J. AND R. BOyd (1998): "The evolution of conformist transmission and the emergence of between-group differences," Evolution and Human Behavior, 19, 215241.

Hsieh, C.-S., M. D. König, X. LiU, And C. Zimmermann (2020): "Collaboration in bipartite networks, with an application to coauthorship networks," Mimeo.

Hsieh, C.-S. AND L. F. LeE (2016): "A social interactions model with endogenous friendship formation and selectivity," Journal of Applied Econometrics, 31, 301-319.

Hsieh, C.-S., L.-F. Lee, And V. Boucher (Forthcoming): "Specification and estimation of network formation and network interaction models with the exponential probability distribution," Quantitative economics.

Keizer, K., S. Lindenberg, And L. Steg (2008): "The spreading of disorder," Science, 322, 1681-1685.

Knecht, A., T. Snijders, C. Baerveldt, And Xxx (2010): "Friendship and delinquency: selection and influence processes in early adolescence," Social Development, 19, 494-514.

Konrad, K. A., T. Lohse, And S. A. Simon (2021): "Pecunia non olet: on the self-selection into (dis)honest earning opportunities," Experimental Economics, Forthcoming. 
Kroher, M. And T. Wolbring (2015): "Social control, social learning, and cheating: Evidence from lab and online experiments on dishonesty," Social Science Research, $53,311-324$.

Lauer, T. And A. Untertrifaller (2019): "Conditional dishonesty," Mimeo.

Lefebvre, M., P. Pestieau, A. Riedl, and M. C. Villeval (2015): "Tax evasion and social information: an experiment in Belgium, France, and the Netherlands," International Tax and Public Finance, 22, 401-425.

Li, S. X. (2020): "Group Identity, Ingroup Favoritism, and Discrimination," in Handbook of Labor, Human Resources and Population Economics, ed. by K. Zimmermann, Springer.

Ludwig, J., G. Duncan, And P. Hirschfield (2001): "Urban poverty and juvenile crime: evidence from a randomized housing-mobility experiment," The Quarterly Journal of Economics, 116, 655-679.

MAnski, C. F. (1993): "Identification of endogenous social effects: The reflection problem," The Review of Economic Studies, 60, 531-542.

McDonald, J. F. And R. A. Moffitt (1980): "The uses of Tobit analysis," The Review of Economics and Statistics, 62, 318-321.

McPherson, M., L. Smith-Lovin, And J. M. Cook (2001): "Birds of a feather: Homophily in social networks," Annual Review of Sociology, 27, 415-444.

Pascual-Ezama, D., D. Dunfield, B. Gil-Gomez de Liano, and D. Prelec (2015): "Peer Effects in Unethical Behavior: Standing or Reputation?" PLOS ONE, 10, e0122305.

Patacchini, E., E. Rainone, And Y. Zenou (2017): "Heterogeneous peer effects in education," Journal of Economic Behavior \&S Organization, 134, 190-227.

Patacchini, E. And Y. Zenou (2009): "Juvenile delinquency and conformism," Journal of Law, Economics, $\&$ Organization, 28, 1-31.

Rauhut, H. (2013): "Beliefs about lying and spreading of dishonesty: Undetected lies and their constructive and destructive social dynamics in dice experiments," PloS ONE, 8, e77878.

Robert, I. And M. Arnab (2013): "Is dishonesty contagious?" Economic Inquiry, 51, $722-734$.

Schrag, J. And S. Scotchmer (1997): "The self-reinforcing nature of crime," International Review of Law and Economics, 17, 325-335.

Ushchev, P. And Y. Zenou (2020): "Social norms in networks," Journal of Economic Theory, 185, 104969.

Xiang, R., J. Neville, And M. Rogati (2010): "Modeling relationship strength in online social networks," in Proceedings of the 19th International Conference on World Wide Web, WWW'10, 981-990. 


\section{A Appendix}

\section{A.1 Instructions and comprehension questionnaires}

\section{A.1.1 Baseline treatment}

Welcome to this experiment on decision making. Please turn your cell phone off. You are not allowed to communicate with the other participants throughout the experiment, in any way, subject to exclusion of the session and cancellation of your earnings. In this experiment, you can earn money. The amount you can earn depends on your decisions. Please read these instructions attentively.

This session comprises several parts. The amount earned at the end of this session is the sum of your payoffs in the different parts. During the session, your payoffs are expressed in points and not in Euros. The conversion rate of points into Euros is: 4 points $=1$ Euro. You will be paid at the end of the session in cash and in private in a separate room.

Your decisions are anonymous: you will never enter your name into the computer. The decisions you will make may be shown to other participants in future experimental sessions, but always in an anonymous way such that it is impossible to identify you personally.

\section{PART 1}

This part comprises 5 periods. One period will be randomly drawn at the end of the session to determine your payoff in this part. During this part, you will have to perform a task.

The task:

This task consists of counting the number of zeros in grids of 5 columns and 5 rows or in grids of 10 columns and 5 rows, containing zeros and ones. The figures below represent examples of grids with 25 figures and grids with 50 figures similar to those you will see on your computer screen.

\begin{tabular}{|l|l|l|l|l|l|l|l|l|l|}
\hline 0 & 0 & 1 & 1 & 0 & 1 & 1 & 1 & 1 & 0 \\
\hline 0 & 0 & 1 & 1 & 0 & 1 & 0 & 0 & 0 & 1 \\
\hline 1 & 1 & 1 & 0 & 0 & 1 & 1 & 0 & 1 & 0 \\
\hline 1 & 1 & 1 & 0 & 0 & 0 & 1 & 0 & 1 & 0 \\
\hline 1 & 0 & 0 & 0 & 0 & 1 & 1 & 1 & 1 & 1 \\
\hline
\end{tabular}

Example of a grid with 10 columns and 5 rows. The correct answer is 23 .

\begin{tabular}{|l|l|l|l|l|}
\hline 0 & 0 & 1 & 1 & 0 \\
\hline 0 & 1 & 0 & 1 & 0 \\
\hline 1 & 1 & 0 & 0 & 0 \\
\hline 0 & 1 & 0 & 0 & 0 \\
\hline 0 & 0 & 0 & 0 & 0 \\
\hline
\end{tabular}

Example of a grid with 5 columns and 5 rows. The correct answer is 18 .

\section{Description of each period:}

Each period lasts two minutes. You will see one grid at a time on your computer screen, and for each grid you are asked to enter the number of zeros you counted in this grid. Then, you have to validate 
your answer by pressing OK.

Whether your answer is correct or not, another grid will appear as soon as you have validated your answer. You have to enter a number and validate it to make a new grid appear. You cannot get back to the previous grid.

A grid is solved if your answer is correct, i.e., if the number of zeros you counted is equal to the solution. A grid solved containing 25 figures pays 1 point. A grid solved containing 50 figures pays 2 points.

During each period, you will see a maximum of 20 grids. All the participants can see the same grids and in the same order as you. The computer program randomly displays grids containing 25 or 50 figures.

At the end of each 2-minute period, a feedback table indicates for each of the 20 grids the value of a solved grid (1 or 2 points), your answer and the correct answer. If your answer is equal to the solution, your answer is considered as correct; otherwise, it is considered as incorrect. If you have not validated an answer for a given grid, a cross appears in all the columns.

\begin{tabular}{|c|c|c|c|c|c|c|c|}
\hline Grid Nb & $\begin{array}{l}\text { Payoff for a } \\
\text { solved grid }\end{array}$ & Your answer & $\begin{array}{l}\text { Correct } \\
\text { answer }\end{array}$ & Grid Nb & $\begin{array}{l}\text { Payoff for a } \\
\text { solved grid }\end{array}$ & Your answer & $\begin{array}{l}\text { Correct } \\
\text { answer }\end{array}$ \\
\hline $\mathbf{1}$ & 1 & 15 & 15 & $\mathbf{1 1}$ & $\mathrm{X}$ & $\mathrm{X}$ & $\mathrm{X}$ \\
\hline $\mathbf{2}$ & 2 & 25 & 25 & $\mathbf{1 2}$ & $\mathrm{X}$ & $\mathrm{X}$ & $\mathrm{X}$ \\
\hline $\mathbf{3}$ & 2 & 24 & 23 & $\mathbf{1 3}$ & $\mathrm{X}$ & $\mathrm{X}$ & $\mathrm{X}$ \\
\hline $\mathbf{4}$ & 1 & 16 & 16 & $\mathbf{1 4}$ & $\mathrm{X}$ & $\mathrm{X}$ & $\mathrm{X}$ \\
\hline $\mathbf{5}$ & 1 & 11 & 10 & $\mathbf{1 5}$ & $\mathrm{X}$ & $\mathrm{X}$ & $\mathrm{X}$ \\
\hline $\mathbf{6}$ & 1 & 10 & 10 & $\mathbf{1 6}$ & $\mathrm{X}$ & $\mathrm{X}$ & $\mathrm{X}$ \\
\hline $\mathbf{7}$ & 1 & 17 & 17 & $\mathbf{1 7}$ & $\mathrm{X}$ & $\mathrm{X}$ & $\mathrm{X}$ \\
\hline $\mathbf{8}$ & 1 & 14 & 14 & $\mathbf{1 8}$ & $\mathrm{X}$ & $\mathrm{X}$ & $\mathrm{X}$ \\
\hline $\mathbf{9}$ & $\mathbf{2}$ & $\mathbf{2 7}$ & $\mathbf{2 7}$ & $\mathbf{1 9}$ & $\mathrm{X}$ & $\mathrm{X}$ & $\mathrm{X}$ \\
\hline $\mathbf{1 0}$ & $\mathrm{X}$ & $\mathrm{X}$ & $\mathrm{X}$ & $\mathbf{2 0}$ & $\mathrm{X}$ & $\mathrm{X}$ & $\mathrm{X}$ \\
\hline
\end{tabular}

\section{Before the first period:}

Before the beginning of the first period, you have to choose between two modes for the calculation of your payoffs: the Direct mode or the Indirect mode.

- In the Direct mode, your payoff in each period is directly calculated by the computer program. After comparing your answer and the correct answer for each grid, the computer program sums the points earned by adding 1 or 2 points per grid solved according to the value indicated in the column "Payoff for a solved grid".

In the Direct mode, the computer program indicates on your screen your payoff for the period and this amount automatically calculated by the program will be paid to you if this period is randomly drawn for payment at the end of the session.

- In the Indirect mode, your payoff in each period is not directly calculated by the computer program. You have to calculate your payoff yourself using the feedback table, as the computer program does in the Direct mode. After comparing your answer and the correct answer for each grid, you have to sum the points earned by adding 1 or 2 points per grid solved according to the value indicated in the column "Payoff for a solved grid". You have at your disposal a pen and a sheet of paper to help you if needed.

In the Indirect mode, you have to enter yourself your payoff for the period on your screen and this amount that you report will be paid to you if this period is randomly drawn for payment at the end of the session.

Below is an example of a feedback table. The payoffs per grid solved and the correct answers are given by way of illustration and do no prejudge the true values during the part. 


\begin{tabular}{|c|c|c|c|c|c|c|c|}
\hline Grid Nb & $\begin{array}{l}\text { Payoff for a } \\
\text { solved grid }\end{array}$ & Your answer & $\begin{array}{l}\text { Correct } \\
\text { answer }\end{array}$ & Grid Nb & $\begin{array}{l}\text { Payoff for a } \\
\text { solved grid }\end{array}$ & Your answer & $\begin{array}{l}\text { Correct } \\
\text { answer }\end{array}$ \\
\hline $\mathbf{1}$ & 1 & 15 & 15 & 11 & $\mathrm{X}$ & $\mathrm{X}$ & $\mathrm{X}$ \\
\hline $\mathbf{2}$ & 2 & 25 & 25 & 12 & $\mathrm{X}$ & $\mathrm{X}$ \\
\hline $\mathbf{3}$ & 2 & 24 & 23 & 13 & $\mathrm{X}$ & $\mathrm{X}$ \\
\hline $\mathbf{4}$ & 1 & 16 & 16 & 14 & $\mathrm{X}$ & $\mathrm{X}$ & $\mathrm{X}$ \\
\hline $\mathbf{5}$ & 1 & 11 & 10 & 15 & $\mathrm{X}$ & $\mathrm{X}$ & $\mathrm{X}$ \\
\hline $\mathbf{6}$ & 1 & 10 & 10 & 16 & $\mathrm{X}$ & $\mathrm{X}$ & $\mathrm{X}$ \\
\hline $\mathbf{7}$ & 1 & 17 & 17 & 17 & $\mathrm{X}$ & $\mathrm{X}$ \\
\hline $\mathbf{8}$ & 1 & 14 & 14 & 18 & $\mathrm{X}$ & $\mathrm{X}$ & $\mathrm{X}$ \\
\hline $\mathbf{9}$ & 2 & 27 & 27 & 19 & $\mathrm{X}$ & $\mathrm{X}$ & $\mathrm{X}$ \\
\hline 10 & $\mathrm{X}$ & $\mathrm{X}$ & $\mathrm{X}$ & $\mathbf{2 0}$ & $\mathrm{X}$ & $\mathrm{X}$ & $\mathrm{X}$ \\
\hline
\end{tabular}

In this example, the person tried to solve 9 grids. S/He solved 7 grids: 5 grids of size 25 and 2 grids of size 50. His/her payoffs are:

Payoff in this period $=(5 \times 1$ point $)+(2 \times 2$ points $)=9$ points.

If you choose the Direct mode, the program will directly indicate the value 9 points. If you choose the Indirect mode, you have to enter the value into your computer.

Attention: you choose the mode only once, and this choice applies to the 5 periods. Once you have chosen one of the two modes, you will not be able to modify your choice.

Before the beginning of the first period and before choosing between the two modes, you will have a chance to test the task during a practice period of 2 minutes to familiarize yourself with the task. This practice period will not be taken into account in the calculation of your payoffs of the part.

To sum up, this part comprises 3 steps:

1. You test the task in a practice period.

2. You choose once between the Direct and the Indirect mode for the calculation of your payoffs.

3. You perform the task during 5 periods.

Please read these instructions again. If you have any questions, raise your hand or press the red button on the side of your desk and we will answer your questions in private.

\section{PART 2}

This part comprises 5 periods. The rules are the same as in part 1, in particular you will have to perform the same task, except that you do not choose your mode of payoff calculation. The mode, Direct or Indirect, which applies is the one you chose at the beginning of part 1 .

If you chose the Direct mode in part 1, your payoff in each period of part 2 is automatically calculated by the computer program. Otherwise, your payoff in each period of this part has to be calculated by yourself, using the feedback table. One period will be randomly drawn at the end of the session to determine your payoff for this part.

Please read these instructions again. If you have any questions, raise your hand or press the red button on the side of your desk and we will answer to your question in private.

\section{PART 3}

This part comprises three questionnaires. Please answer these questions. Do not spend too much time on each question, answer spontaneously and sincerely. Your answers to these questionnaires are anonymous and confidential and will never be transferred to other participants. Completing these questionnaires yields a payoff of 2 Euros.

\section{END OF THE SESSION}


After you complete the questionnaires, we will ask you a few socio-demographic questions and questions about the session. Finally, you will be informed on your screen of your payoff in each part and of your total payoff for the session. Your total payoff is calculated as follows:

Final payoff $=$ payoff for the task in part $1+$ payoff for the task in part 2

$$
+2 \text { Euros for the questionnaires }+5 \text { Euros as a show-up fee }
$$

Then, please remain seated until an experimenter invites you to proceed to a separate room for your payment. You will be called one by one. Please, bring your computer tag and your receipt of payment.

\section{A.1.2 EXO treatment}

Parts 1 and 3 are the same as in the Baseline treatment.

\section{PART 2}

This part comprises 5 periods. The rules are the same as in part 1, in particular you have to perform the same task, except that you do not choose your mode of payoff calculation. The mode which applies, Direct or Indirect, is the one you chose at the beginning of part 1 .

If you chose the Direct mode in part 1, your payoff in each period of part 2 is automatically calculated by the computer program. Otherwise, your payoff in each period of this part has to be calculated by yourself, using the feedback table. A period will be randomly drawn at the end of the session to determine your payoff for this part.

Before the task:

- Information on 4 participants from a past session:

Before starting performing the task, the computer program will match each of you with four participants from a past session: two participants who chose the Direct mode and two participants who chose the Indirect mode. These people are not present in the laboratory today. Your screen will display the average payoff in part 1 of these two participants who chose the Direct mode and the average payoff of these two participants who chose the Indirect mode.

- Matching process:

Next, the computer program will match you randomly with one of these two pairs: you have a $50 \%$ chance to be matched with the two participants who chose the Direct mode and a $50 \%$ chance to be matched with the two participants who chose the Indirect mode. This pair will be called your "peers": we will call them peers of Direct type or peers of Indirect type, depending on which pair has been assigned to you by the computer program.

Description of each period:

During the counting task, in each period you will see the average payoff of your peers from a past session in the same period in part 2. Precisely, you will be able to observe the average payoff of your peers in this period, i.e., their payoff calculated by the computer program if your peers are of Direct type, or their payoff calculated and reported by themselves if your peers are of indirect type.

Examples:

- In period 1 , if the program assigned you peers of Direct type, the program will inform you of the average payoff of your peers calculated by the program in period 1 of part 2 . In period 4 , it will inform you of their average payoff in period 4 .

- Similarly, in period 1, if the program assigned you peers of Indirect type, the program will inform you of the average payoff of your peers calculated by themselves in period 1 of part 2 . In period 3 , it will inform you of their average payoff in period 3. 
Unlike you, these peers were not matched with other participants and thus, they did not receive any information on the choices or payoffs of other participants. In each period, they saw the same grids as you and in the same order as you.

In each period, you will be informed of the average payoff in that period of the pair of peers that has been assigned to you. In contrast, you will not be informed of the average payoff in that period of the pair of peers that has not been assigned to you; nevertheless, you will be informed at the end of the session of the average payoff in each period of the pair of peers that has not been assigned to you.

Your payoffs are computed according to the mode you chose in part 1 . The payoff of your peers are not taken into account in the calculation of your payoffs.

To sum up, this part comprises 2 steps:

1. Your screen displays the average payoff in part 1 of two participants from a past session who chose the Direct mode of the task and two participants who chose the Indirect mode. The program matches you with one of these two pairs.

2. You perform the task for 5 periods. During each period, you can observe the payoff of your two peers in the same period in part 2.

Please read these instructions again. If you have any questions, raise your hand or press the red button on the side of your desk and we will answer to your questions in private.

\section{A.1.3 ENDO treatment}

Parts 1 and 3 are the same as in the Baseline treatment.

\section{PART 2}

This part comprises 5 periods. The rules are the same as in part 1, in particular you have to perform the same task, except that you do not choose your mode of payoff calculation. The mode which applies, Direct or Indirect, is the one you chose at the beginning of part 1.

If you chose the Direct mode in part 1, your payoff in each period of part 2 is automatically calculated by the computer program. Otherwise, your payoff in each period of this part has to be calculated by yourself, using the feedback table. A period will be randomly drawn at the end of the session to determine your payoff for this part.

Before the task:

- Information on 4 participants of a past session:

Before starting performing the task, the computer program will match each of you with 4 participants from a past session: two participants who chose the Direct mode and two participants who chose the Indirect mode. These people are not present in the laboratory today. Your screen will display the average payoff in part 1 of these two participants who chose the Direct mode and the average payoff of these two participants who chose the Indirect mode.

- Choice of peers: Next, you will choose one of these two pairs. This pair will be called your "peers": we will call them peers of Direct type or peers of Indirect type, depending on which pair you have chosen.

Description of each period:

During the counting task, in each period you will see the average payoff of your peers from a past session in the same period in part 2. Precisely, you will be able to observe the average payoff of your peers in this period, i.e., their payoff calculated by the computer program if your peers are of Direct type, or their payoff calculated and reported by themselves if your peers are of indirect type.

Examples: 
- In period 1, if you chose peers of Direct type, the program will inform you of the average payoff of your peers calculated by the program in period 1 of part 2 . In period 4 , it will inform you of their average payoff in period 4 .

- Similarly, in period 1 , if you chose peers of Indirect type, the program will inform you of the average payoff of your peers calculated by themselves in period 1 of part 2 . In period 3 , it will inform you of their average payoff in period 3 .

Unlike you, these peers were not matched with other participants and thus, they did not receive any information on the choices or payoffs of other participants. In each period, they saw the same grids as you and in the same order as you.

In each period, you will be informed of the average payoff in that period of the pair of peers that you have chosen. In contrast, you will not be informed of the average payoff in that period of the pair of peers that you have not chosen; nevertheless, you will be informed at the end of the session of the average payoff in each period of the pair of peers that you have not chosen.

Your payoffs are computed according to the mode you chose in part 1. The payoff of your peers are not taken into account in the calculation of your payoffs.

To sum up, this part comprises 2 steps:

1. Your screen displays the average payoff in part 1 of two participants from a past session who chose the Direct mode of the task and two participants who chose the Indirect mode. You choose one of these two pairs.

2. You perform the task during 5 periods. During each period, you can observe the payoff of your two peers in the same period in part 2 .

Please read these instructions again. If you have any questions, raise your hand or press the red button on the side of your desk and we will answer your questions in private.

\section{A.2 Comprehension questionnaires}

The questionnaires are composed of True/False questions. The questionnaire used after reading the instructions for part 1 was the same for all treatments. An additional questionnaire was used after reading the instructions for part 2 for participants in the ENDO and the EXO treatments.

\section{A.2.1 Questionnaire in Part 1}

1. The grids you have to solve differ across participants. False.

2. If you give an incorrect answer for a grid, you can make a new attempt. False.

3. One period out of the five periods will be randomly drawn at the end of the session to determine your earnings for this part. True.

4. You will choose at the beginning of each period one of the two modes for the calculation of your payoffs. False.

5. If you choose the Direct mode, the program will directly compute your payoffs in each period. True.

6. If you choose the Indirect mode, you compute yourself your payoffs in each period. True.

\section{A.2.2 Questionnaire in Part 2: EXO treatment}

1. The computer program will randomly match you either with two participants who chose the Direct mode or with two participants who chose the Indirect mode. True.

2. These participants are present in the laboratory today. False. Additional comment if they answered incorrectly: They participated in previous sessions.

3. These participants did not receive any information on the choices or the earnings of other participants. True. Additional comment if they answered incorrectly: In these sessions, the participants were not matched with other participants. 
4. At each period, the program will inform you about the payoffs of each peer in the corresponding period. False. Additional comment if they answered incorrectly: The program will inform you about the average payoffs of your peers in the corresponding period.

5. Your peers did not see exactly the same grids as you. False. Additional comment if they answered incorrectly: Your peers saw exactly the same grids, in the same order as you.

\section{A.2.3 Questionnaire in Part 2: ENDO treatment}

1. You will choose either two participants who chose the Direct mode or two participants who chose the Indirect mode. True.

2. These participants are present in the laboratory today. False, Additional comment if they answered incorrectly: They participated in previous sessions.

3. These participants did not receive any information on the choices or the earnings of other participants. True. Additional comment if they answered incorrectly: In these sessions, the participants were not matched with other participants.

4. At each period, the program will inform you about the payoffs of each peer in the corresponding period. False. Additional comment if they answered incorrectly: The program will inform you about the average payoffs of your peers in the corresponding period.

5. Your peers did not see exactly the same grids as you. False. Additional comment if they answered incorrectly: Your peers saw exactly the same grids, in the same order as you. 


\section{A.3 Appendix Figures}

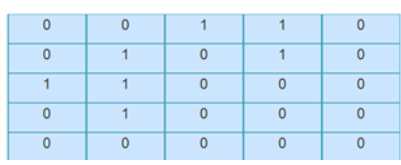

Figure A.1: Example of a $5 \times 5$ grid

\begin{tabular}{|l|l|l|l|l|l|l|l|l|l|}
\hline 0 & 0 & 1 & 1 & 0 & 1 & 1 & 1 & 1 & 0 \\
\hline 0 & 0 & 1 & 1 & 0 & 1 & 0 & 0 & 0 & 1 \\
\hline 1 & 1 & 1 & 0 & 0 & 1 & 1 & 0 & 1 & 0 \\
\hline 1 & 1 & 1 & 0 & 0 & 0 & 1 & 0 & 1 & 0 \\
\hline 1 & 0 & 0 & 0 & 0 & 1 & 1 & 1 & 1 & 1 \\
\hline
\end{tabular}

Figure A.2: Example of a $5 \times 10$ grid

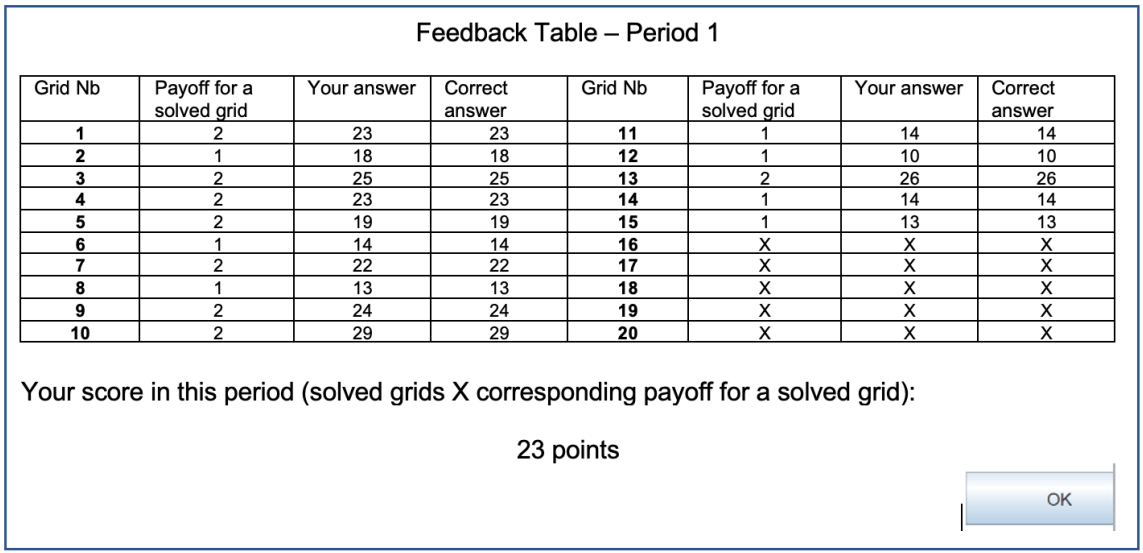

Figure A.3: Example of a Feedback Table - Automatic Mode

\begin{tabular}{|c|c|c|c|c|c|c|c|}
\hline \multicolumn{8}{|c|}{ Feedback Table - Period 1} \\
\hline Grid Nb & $\begin{array}{l}\text { Payoff for a } \\
\text { solved grid }\end{array}$ & Your answer & $\begin{array}{l}\text { Correct } \\
\text { answer }\end{array}$ & Grid Nb & $\begin{array}{l}\text { Payoff for a } \\
\text { solved grid }\end{array}$ & Your answer & \begin{tabular}{|l|}
$\begin{array}{l}\text { Correct } \\
\text { answer }\end{array}$ \\
\end{tabular} \\
\hline 1 & 2 & 23 & 23 & 11 & 1 & 14 & 14 \\
\hline 2 & 1 & 18 & 18 & 12 & 1 & 10 & 10 \\
\hline 3 & 2 & 25 & 25 & 13 & 2 & 26 & 26 \\
\hline 4 & 2 & 23 & 23 & 14 & 1 & 14 & 14 \\
\hline 5 & 2 & 19 & 19 & 15 & 1 & 13 & 13 \\
\hline 6 & 1 & 14 & 14 & 16 & $x$ & $x$ & $x$ \\
\hline 7 & 2 & 22 & 22 & 17 & $x$ & $x$ & $x$ \\
\hline 8 & 1 & 13 & 13 & 18 & $x$ & $x$ & $x$ \\
\hline 9 & 2 & 24 & 24 & 19 & $x$ & $x$ & $x$ \\
\hline 10 & 2 & 29 & 29 & 20 & $x$ & $x$ & $X$ \\
\hline \multicolumn{8}{|c|}{ What is your score in this period (solved grids $X$ corresponding payoff for a solved grid)? } \\
\hline & & & & & & & OK \\
\hline
\end{tabular}

Figure A.4: Example of a Feedback Table - Manual Mode

C.1 


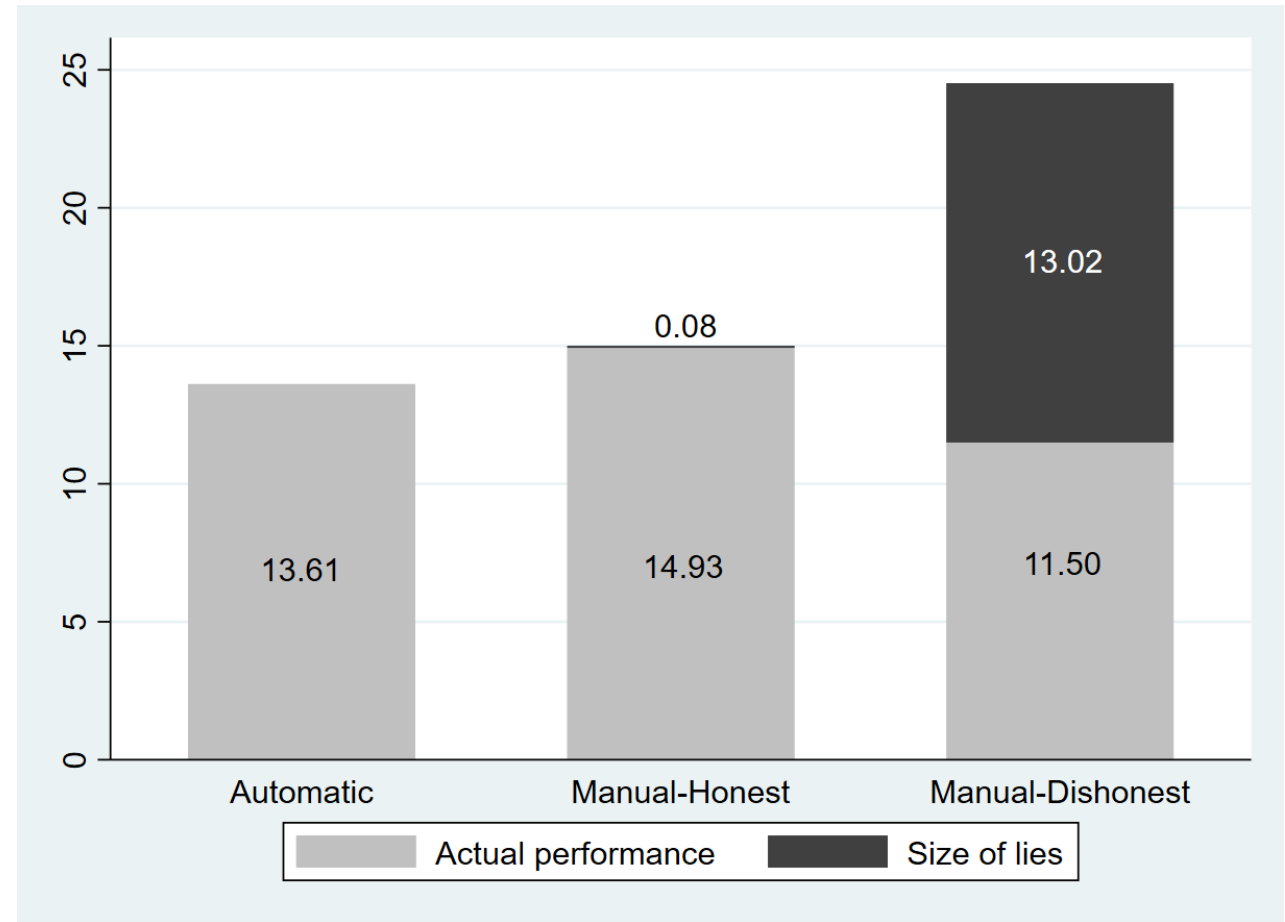

Figure A.5: Average Actual Performance and Size of Lies in Part 1: Automatic, ManualHonest, and Manual-Dishonest Participants, Pooled Treatments

\section{A.4 Appendix Tables}

Table A.1: Summary of the Sessions

\begin{tabular}{ccc}
\hline Session & Treatment & Number of Participants \\
\hline Session 1 & Baseline & 18 \\
Session 2 & Baseline & 22 \\
Session 3 & Baseline & 17 \\
Session 4 & Baseline & 15 \\
Session 5 & ENDO & 23 \\
Session 6 & ENDO & 23 \\
Session 7 & ENDO & 30 \\
Session 8 & ENDO & 27 \\
Session 9 & ENDO & 27 \\
Session 10 & EXO & 26 \\
Session 11 & EXO & 31 \\
Session 12 & EXO & 23 \\
Session 13 & EXO & 27 \\
Session 14 & ENDO & 24 \\
Session 15 & EXO & 19 \\
Session 16 & EXO & 17 \\
\hline Total & & 369 \\
\hline
\end{tabular}


Table A.2: Summary Statistics: Individual Characteristics

\begin{tabular}{|c|c|c|c|c|c|c|}
\hline Treatment & Baseline & EXO & ENDO & $\begin{array}{c}p \text {-value } \\
\text { EXO/ENDO }\end{array}$ & $\begin{array}{c}p \text {-value } \\
\text { Base/EXO }\end{array}$ & $\begin{array}{c}p \text {-value } \\
\text { Base/ENDO }\end{array}$ \\
\hline Age & $\begin{array}{l}23.74 \\
(6.55)\end{array}$ & $\begin{array}{l}21.80 \\
(6.23)\end{array}$ & $\begin{array}{l}22.86 \\
(7.83)\end{array}$ & 0.197 & 0.034 & 0.413 \\
\hline Male (\%) & $\begin{array}{c}36.11 \\
(0.484)\end{array}$ & $\begin{array}{c}53.85 \\
(0.500)\end{array}$ & $\begin{array}{c}50.65 \\
(0.501)\end{array}$ & 0.583 & 0.014 & 0.041 \\
\hline Student (\%) & $\begin{array}{c}80.55 \\
(0.398)\end{array}$ & $\begin{array}{c}95.80 \\
(0.201)\end{array}$ & $\begin{array}{c}92.21 \\
(0.269)\end{array}$ & 0.196 & $<0.001$ & 0.010 \\
\hline Business (\%) & $\begin{array}{c}30.55 \\
(0.464)\end{array}$ & $\begin{array}{c}56.64 \\
(0.497)\end{array}$ & $\begin{array}{c}61.69 \\
(0.488)\end{array}$ & 0.378 & $<0.001$ & $<0.001$ \\
\hline Degree & $\begin{array}{l}6.29 \\
(1.73)\end{array}$ & $\begin{array}{c}5.72 \\
(1.70)\end{array}$ & $\begin{array}{c}5.75 \\
(1.46)\end{array}$ & 0.885 & 0.022 & 0.015 \\
\hline $\begin{array}{l}\text { Monthly } \\
\text { expenses }\end{array}$ & $\begin{array}{c}819.58 \\
(375.10)\end{array}$ & $\begin{array}{c}836.48 \\
(381.24)\end{array}$ & $\begin{array}{c}849.13 \\
(292.54)\end{array}$ & 0.747 & 0.758 & 0.520 \\
\hline $\begin{array}{c}\text { First } \\
\text { participation (\%) }\end{array}$ & $\begin{array}{c}36.11 \\
(0.484)\end{array}$ & $\begin{array}{c}51.05 \\
(0.502)\end{array}$ & $\begin{array}{c}66.88 \\
(0.472)\end{array}$ & 0.005 & 0.038 & $<0.001$ \\
\hline $\mathrm{N}$ & 72 & 143 & 154 & & & \\
\hline
\end{tabular}

Notes: Standard deviations are in parentheses. $p$-value indicates the $p$-value from t-tests on the pairwise differences between treatments. The sample of participants in the Baseline differs from the other treatments (significantly older and more experienced subjects, less males, less students from the business school). This is why we control for these differences in the regressions. The differences are not significant between EXO and ENDO. Note that all the peers in EXO and ENDO come from the same pool of participants in the Baseline. Thus, the composition of the sample in the Baseline could not introduce differences between EXO and ENDO. 
Table A.3: Probability of Choosing the Manual Mode

\begin{tabular}{lcc}
\hline \hline Dep. var.: Choosing Manual & $(1)$ & $(2)$ \\
\hline$D_{E N D O}$ & - & 0.031 \\
& & $(0.078)$ \\
$D_{E X O}$ & - & 0.046 \\
Age & $(0.077)$ \\
& $-0.013^{*}$ & $-0.014^{*}$ \\
Male & $(0.007)$ & $(0.008)$ \\
& 0.046 & 0.042 \\
Degree & $(0.053)$ & $(0.054)$ \\
& 0.026 & 0.028 \\
Student & $(0.018)$ & $(0.018)$ \\
& 0.121 & 0.106 \\
Business & $(0.158)$ & $(0.160)$ \\
& 0.039 & 0.035 \\
Monthly expenses & $(0.063)$ & $(0.064)$ \\
& 0.080 & 0.080 \\
First participation & $(0.085)$ & $(0.085)$ \\
& -0.041 & -0.042 \\
$N$ & $(0.058)$ & $(0.060)$ \\
\hline Log-Likelihood & 369 & 369 \\
\hline \hline
\end{tabular}

Notes: This table reports the marginal effects from Probit models in which the dependent variable is the binary choice of the Manual mode. There is one observation per individual. Standard deviations are in parentheses. $D_{E N D O}$ and $D_{E X O}$ are the respective dummy variables for the ENDO and the EXO treatments; the Baseline is the reference group. Age is the age of the participant in years. Male is a binary variable equal to 1 for males, and 0 otherwise. Degree represents the level of degree of the participant, from 0 for no degree up to 9 for a $\mathrm{PhD}$ candidate. Student is a binary variable equal to 1 if the participant is a student. Business is a binary variable equal to 1 if the participant is a student and studies at the business school. Monthly expenses represents the selfreported monthly expenses in Euros $\times 10^{-3}$. First participation is a binary variable equal to 1 if the subject participated in an experiment for the first time. ${ }^{*} \mathrm{p}<0.1$. 
Table A.4: Determinants of the Size of Lies in Part 1 for Participants who Chose the Manual Mode

\begin{tabular}{lccc}
\hline \hline Dep. var.: & Pooled & EXO & ENDO \\
Size of Lie - Part 1 & $(1)$ & $(2)$ & $(3)$ \\
\hline$D_{E X O}$ & 1.378 & - & - \\
& $(1.848)$ & & \\
$D_{E N D O}$ & 0.620 & - & - \\
& $(1.856)$ & & \\
Age & $0.392^{*}$ & 0.368 & $0.700^{* *}$ \\
& $(0.229)$ & $(1.173)$ & $(0.333)$ \\
Male & 1.862 & 3.136 & 0.495 \\
& $(1.274)$ & $(2.378)$ & $(1.481)$ \\
Degree & $1.159^{* *}$ & 0.128 & 1.006 \\
& $(0.485)$ & $(1.133)$ & $(0.733)$ \\
Student & 7.937 & 54.48 & 16.58 \\
& $(4.838)$ & $(6070.9)$ & $(11.42)$ \\
Business & 1.333 & -0.0945 & 3.405 \\
& $(1.561)$ & $(2.671)$ & $(2.225)$ \\
Monthly expenses & 0.002 & 0.003 & $-0.005^{*}$ \\
& $(0.002)$ & $(0.003)$ & $(0.003)$ \\
First participation & $-2.991^{* *}$ & -3.290 & $-3.750^{*}$ \\
& $(1.349)$ & $(2.367)$ & $(1.937)$ \\
\hline \hline$N$ & 885 & 365 & 365 \\
Left-censored obs. & 446 & 171 & 184 \\
Log-likelihood & -1801.49 & -787.25 & -722.17 \\
\hline \hline & & & \\
\hline
\end{tabular}

Notes: This table reports the marginal effects from RE Tobit models with standard errors are in parentheses. The dependent variable is the size of lies in each period of part 1 . There are five observations per individual. $D_{E N D O}$ and $D_{E X O}$ are dummy variables equal to 1 respectively for ENDO and EXO, and 0 otherwise; the Baseline is the reference group. Age is the age of the participant in years. Male is a binary variable equal to 1 for males. Degree represents the level of degree of the participant, from 0 for no degree up to 9 for a $\mathrm{PhD}$ candidate. Student is a binary variable equal to 1 if the participant is a student. Business is a binary variable equal to 1 if the participant is a student and studies at the business school. Monthly expenses represents the self-reported monthly expenses in Euros. First participation is a binary variable equal to 1 if the subject participated in an experiment for the first time. ${ }^{*} \mathrm{p}<0.1,{ }^{* *} \mathrm{p}<0.05$. 


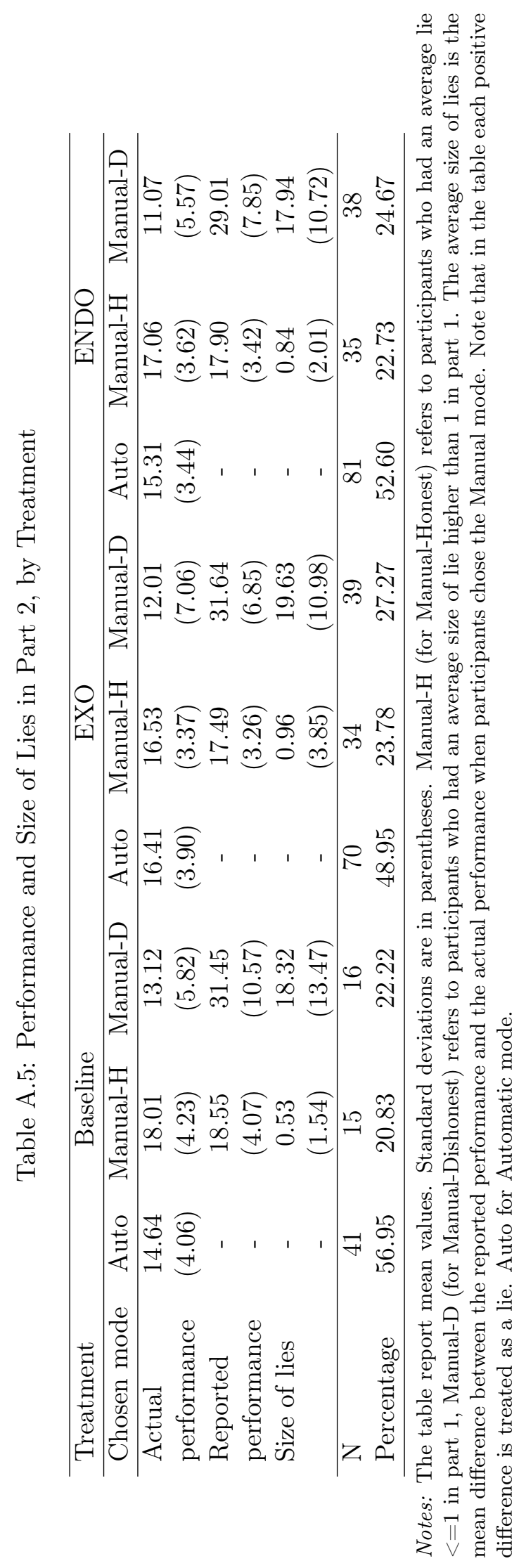

D. 5 
Table A.6: Peer Effects on the Lies of Participants who Chose the Manual Mode (Part 2) - Robustness Test with a Different Definition of Manual-H and Manual-D

\begin{tabular}{|c|c|c|c|c|c|}
\hline $\begin{array}{l}\text { Dep. var.: } \\
\text { Size of Lies -Part } 2\end{array}$ & (1) Manual & $\begin{array}{l}\text { (2) Manual } \\
\text { Auto peers }\end{array}$ & $\begin{array}{l}\text { (3) Manual } \\
\text { Manual peers }\end{array}$ & $\begin{array}{l}\text { (4) Manual-H } \\
\text { Manual peers }\end{array}$ & $\begin{array}{l}\text { (5) Manual-D } \\
\text { Manual peers }\end{array}$ \\
\hline $\begin{array}{l}\text { (AUTO) Peers' } \\
\text { actual perf. }\end{array}$ & $\begin{array}{l}-0.005 \\
(0.123)\end{array}$ & $\begin{array}{l}-0.062 \\
(0.110)\end{array}$ & - & - & - \\
\hline $\begin{array}{l}\text { (MANUAL) Peers' } \\
\text { reported perf. }\end{array}$ & $\begin{array}{c}0.194^{* *} \\
(0.076)\end{array}$ & & $\begin{array}{l}0.229^{*} \\
(0.117)\end{array}$ & $\begin{array}{l}-0.106 \\
(0.138)\end{array}$ & $\begin{array}{c}0.382^{* *} \\
(0.159)\end{array}$ \\
\hline $\begin{array}{l}\text { Individual } \\
\text { characteristics }\end{array}$ & Yes & Yes & Yes & Yes & Yes \\
\hline$N$ & 365 & 175 & 190 & 70 & 120 \\
\hline Log-likelihood & -761.18 & -297.83 & -458.46 & -68.18 & -370.08 \\
\hline
\end{tabular}

Notes: This table reports the marginal effects from RE Tobit regressions with standard errors are in parentheses. The dependent variable is the size of lies in each period of part 2 . There are five observations per individual. The marginal effects are calculated as the average marginal effects over time and over individuals. This table is built like Table 2 reported in the main text, except that the categories of Manual-Honest and Manual-Dishonest participants are defined in reference to a different cutoff point. Here, a Manual-Dishonest subject is defined as a participant who reported on average more than two more earnings points than his actual performance per period in part 1 (instead of more than one in Table 2. None of the individual characteristics are significant. ${ }^{* *}$ $p<0.05,{ }^{* * *} \quad p<0.01$. 
Table A.7: Size of Lies and Homophily - Robustness Test with a Different Definition of Manual-H and Manual-D

\begin{tabular}{lccc}
\hline \hline Dep. var.: & MANUAL-ALL & MANUAL-H & MANUAL-D \\
Size of Lies - Part 2 & $(1)$ & $(2)$ & $(3)$ \\
\hline (MANUAL) Peers' Reported & $0.191^{* * *}$ & 0.008 & $0.182^{* *}$ \\
Performance & $(0.061)$ & $(0.028)$ & $(0.092)$ \\
(MANUAL) Peers' Reported & 0.006 & 0.014 & 0.133 \\
Performance $\times D_{E N D O}$ & $(0.088)$ & $(0.039)$ & $(0.149)$ \\
$D_{E N D O}$ & -1.444 & -0.193 & -4.765 \\
& $(2.197)$ & $(0.800)$ & $(3.616)$ \\
\hline Individual characteristics & $Y e s$ & $Y e s$ & $Y e s$ \\
\hline$N$ & 730 & 370 & 360 \\
Log-likelihood & 1487.10 & -346.71 & -1069.85 \\
\hline \hline
\end{tabular}

Notes: This table reports the marginal effects from RE Tobit regressions with standard errors in parentheses. The dependent variable is the size of lies in each period of part 2. There are five observations per individual. The marginal effects are calculated as the average marginal effects over time and over individuals. This table is built like Table 4 reported in the main text, except that the categories of Manual-Honest and Manual-Dishonest participants are defined in reference to a different cutoff point. Here, a Manual-Dishonest subject is defined as a participant who reported on average more than two more earnings points than his actual performance per period in part 1 (instead of more than one in Table 4). First participation is the sole significant individual characteristic (in model (1) at the $1 \%$ level). ${ }^{* *} p<0.05,{ }^{* * *} p<0.01$.

Table A.8: Peer Effects on the Actual Performance of Participants who Chose the Automatic Mode (Part 2)

\begin{tabular}{lccc}
\hline \hline Dep. var.: & Pool & EXO & ENDO \\
Actual performance & $(1)$ All & $(2)$ All & $(3)$ All \\
\hline (AUTO) Peers' actual & -0.004 & -0.032 & 0.032 \\
performance & $(0.052)$ & $(0.076)$ & $(0.072)$ \\
(MANUAL) Peers' reported & 0.043 & 0.041 & 0.045 \\
performance & $(0.037)$ & $(0.053)$ & $(0.050)$ \\
Constant & $14.65^{* * *}$ & $14.39^{* * *}$ & $14.78^{* * *}$ \\
& $(3.017)$ & $(4.600)$ & $(3.622)$ \\
\hline Individual characteristics & $Y e s$ & $Y e s$ & $Y e s$ \\
\hline$N$ & 755 & 350 & 405 \\
Chi2 & 17.84 & 12.65 & 7.329 \\
\hline \hline
\end{tabular}

Notes. This table reports the coefficients from OLS regressions with panel robust standard errors in parentheses. The dependent variable is the actual performance in each period of part 2 . There are five observations per individual. (AUTO) Peers' actual performance is the average actual performance observed in the period from the two peers that selected the Automatic mode (its coefficient corresponds to marginal effect associated with $\lambda_{1} /\left(1+\lambda_{1}\right)$ in the model). (MANUAL) Peers' reported performance is the average reported performance observed in the period from the two peers that selected the Manual mode (its coefficient corresponds to the marginal effect associated with $\lambda_{2} \delta /\left(1+\lambda_{2}\right)$ in the model). The socio-demographic variables include the participant's age in years, gender, educational achievement (from 0 to 9), student status, being a student in business, monthly expenses, and a binary variable for a first participation in an economic experiment. None of the individual characteristics are significant at the $5 \%$ level or less. ${ }^{* * *} \mathrm{p}<0.01$. 


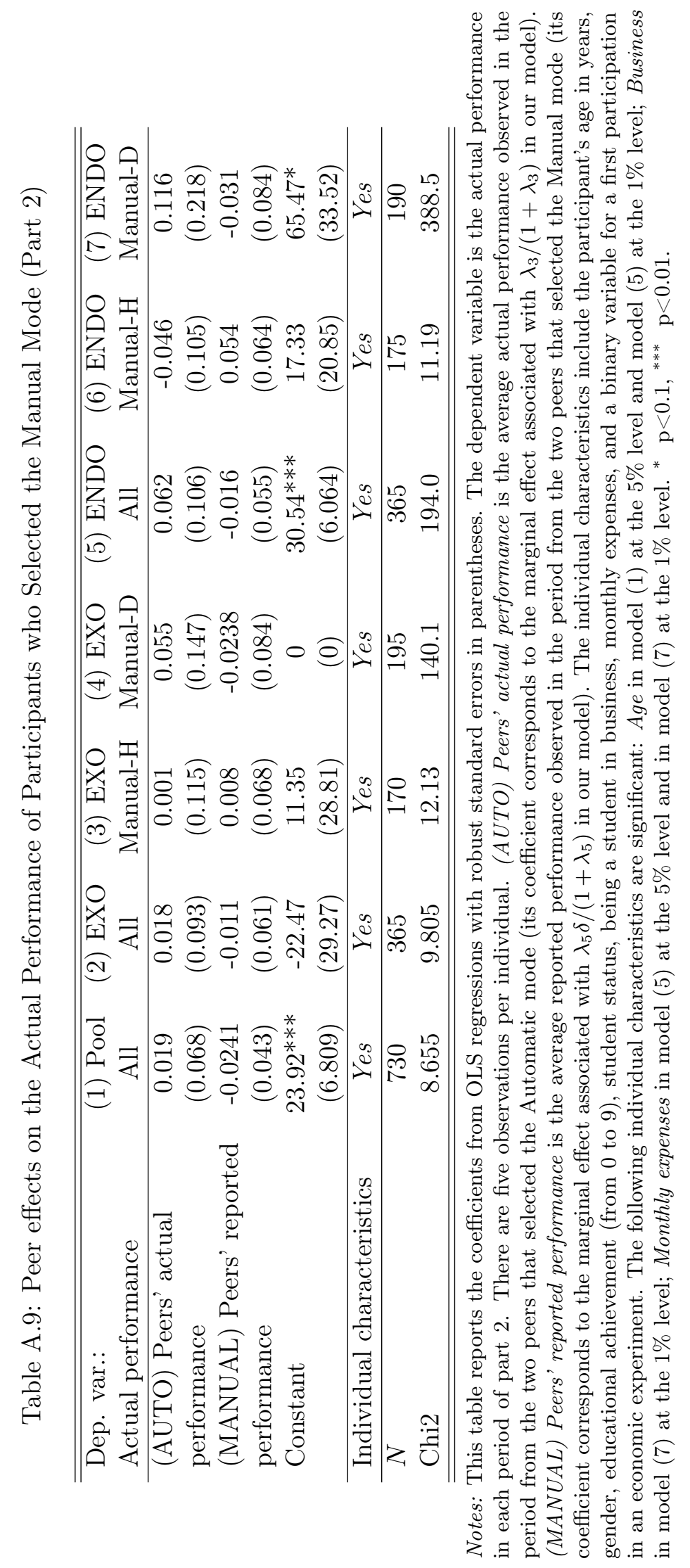

